report no. AES-85-90

\title{
DEVELOPMENT OF CHARCOAL SORBENTS FOR HELIUM CRYOPUMPING
}

\author{
prepared for \\ Lawrence Livermore National Laboratory \\ in response to \\ PO 2024005 of Contract W-7405-ENG-48 \\ daled 24 May 1984 \\ by \\ D. W. Sedgley \& A. G. Tobin \\ Grumman Aerospace Corporation \\ Bethpage, NY 11714
}

UCRL $-15623-85$

DE87 003889

\section{DISCLAIMER}

This report was prepared as an account of work sponsored by an agency of the United Stales Government. Neither the United States Government nor any agency thereof, nor any oi their employec $i_{1}$ makes any warranty, express or implied, or assumes any legal liability or responsibility for the accuracy, completeness, or usefulness of any information, apparatus, product, or process disclosed, or represents that its use would nol infringe privately owned rights. Refefence herein to any sjecific commercial product, process, or service by trade name, trademark. manufacturer, or otherwise does not necessarily constitute or imply its endorsement, recommendation, of favoring by the United States Government or any agency thereof. The views and opinions of authors expressed herein do not necessarily state or reflect those of the United States Government or any agency thereof. 
CONTENTS

Section $\quad \underline{\text { Page }}$

1

SUMMARY ...................... 1-1

2 INTRODUCTION ........................ 2-1

o OBJECTIVE ...................... 3-1

4 EVAlUATION OF BONDING AGENTS .............. 4-1

4.1 Optimization of Sil-Fos Braze Bond . . . . . . . . . . 4-3

4.2 Optinization of Copper Cement Bond. . . . . . . . . . 4-3

4.3 Optimization of Charcoal Particle Size Distribution . . . . . . 4-3

4.4 Optimization of Copper Substrate Thickness . . . . . . . 4-4

5 SCALE-UP FOR TSTA OF OPTIMIZED BONDING ACENTS . . . . 5-1

5.1 Preparation of TSTA Specimen. . . . . . . . . . . 5-1

5.2 Design Development of 16 in. Diameter TSTA Test Specinien .................... 5-3

6 TEST PROGRAM .................... 6-

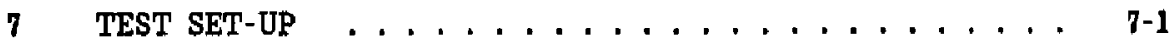

7.1 Test Apparatus ................... 7-1

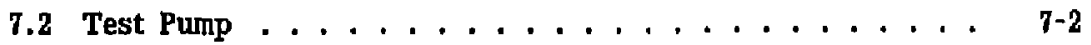

7.3 Test Dewar . . . . . . . . . . . . . . . 7-3

7.4 Test Article . . . . . . . . . . . . . . . 7-4

7.5 Instrumentation ................. 7-5

8 TEST METHOD ..................... 8-1

8.1 Testing of 4 in. $(10.2 \mathrm{Cm})$ Samples . . . . . . . . 8-1

8.2 Testing of $16 \mathrm{in.}(40.6 \mathrm{Cm})$ Diameter Panel ....... 8-2 


\section{CONTENTS (contd)}

Section

$\underline{\text { Page }}$

9

TEST RESULTS $\ldots \ldots \ldots \ldots \ldots \ldots \ldots$. . . . . . . . .

9.1 Evaluation of Charcoal Particle Size . . . . . . . . 9-1

9.2 Thermal Cycle Tests. . . . . . . . . . . . . . 9-2

9.3 Environmental Tests. . . . . . . . . . . . . . 9-4

9.3.1 Charcoal Sample with Braze Bond (No. 110) . . . . 9-6

9.3.2 Charcoal Sample with Cement Bond (No. 111) . . . . 9-8

9.4 TSTA Panel Tests. . . . . . . . . . . . . . . . 9-10

10 CHARACTERIZATION OF CHARCOAL .......... 10-1

11 DISCUSSION OF RESULTS . . . . . . . . . . . 11-1

12 CONCLUSIONS \& RECOMMENDATIONS $\ldots \ldots \ldots \ldots \ldots \ldots$. . . . .

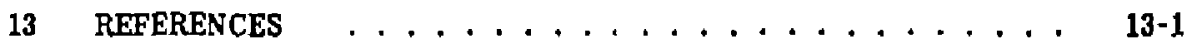




\section{ILLUSTRATIONS}

Fig. $\quad$ Page

5-1 Kanthal Retainer Shown in Place to Retain Charcoal During Brazing . 5-2

5-2 Arrangement of Copper Plates for TSTA Pumping Panel. . . . . . 5-3

5-3 $40 \mathrm{Cm}$ Charcoal Cryopanel Installed on Dewar. . . . . . . . . 5-4

7-1 Test System Schenatic ................... 7-1

7*2 Workhorse Cryopump for Charcoal Sorbent Tests ........... 7-2

7-3 Charcoal Panel Installed in Workhorse Cryopump .......... 7-3

7-4 Charcoal Compound Cryopump ................ 7-4

7-5 TSTA Dewar in the LLNL Vacuum Chamber. . . . . . . . . T-5

9-1 Helium Pumping Performance of Coconut Charcoal Bonded with 3-Mil Sil-Fos Braze. . . . . . . . . . . . . . . . 9-3

9-2 Helium Pumping Performance of Coconut Charcoal with 6-Mil Sol-Fos Braze. . . . . . . . . . . . . . . . . . 9-4

9-3 Helium Pumping Performance of Coconut Charcoal Bonded with 9-Mil Sil-Fos Braze Layer. . . . . . . . . . . . . 9 9-5

9-4 Helium Pumping Performance of Coconut Charcoal Bonded with Undiluted Copper Cement. . . . . . . . . . . . . . . . 9-6

9-5 Effect of Vacuum Exposure History on Helium Pumping Performance of Coconut Charcoal Bonded by 6-Mil Sil-Fos Braze . . . . . . . . 9-1

9-6 Effect of Vacuum Exposure History on Charcoal Pumping Performance of Copper Cement Bonded Charcoal. . . . . . . . . . . . . 9-9

9-7 Helium Pumping Performance of Scaled-up 40-Cm Dia Charcoal Cryopump Bonded with 6-Mil Sil-Fos Braze . . . . . . . . . 9-11

10-1 Microstructure of Charcoal Granules .............. 10-2

\section{TABLES}

Table

4-1 Braze Alloy Compositions Evaluated for Compatibility with Charcoal ....................... 4-1

4-2 Description of Charcoal Samples ................. 4-2 


\section{1 - SUMMARY}

Improved methods for cryopumping helium were developed for application to fusion reactors whare high helium generation rates are expected. This study period evaluated charcoal particle size, bonding agent type and thickness, and substrate thickness. The optimum combination of charcoal, bond, and substrate was used to form a sealed-up panel for evaluation in the Tritium Systems Test Assembly (TSTA) at Los Alamos.

The optimum combination is a $12 \times 30$ mesh coconut charcoal attached to $0.48 \mathrm{~cm}$ thick copper substrate by a 0.015 em thick silver phosphorus copper braze. The scaled-up panel was at tached to a TSTA compound pump dewar and tested for helium pumping performance in an LN-shielded chamber. Based on the tests, the projected helium pumping performance for the of timum charcoal panel, assembled as a double chevron compound pump, is 4.9 liter $\sec ^{-1} \mathrm{em}^{-2}$.

A copper cement bond for attaching charcoal to a substrate was identified and tested. Helium pumping performance of this combination was comparable to that of the charcoal braze system. Evaluation of the cement is less mature than that of the braze, but the cement offers manufacturing flexibility that makes further study worthwhile.

Environnenta! tests showed the charcoal's susceptibility to vacuum chamber contamination. Performance degradation followed exposure of ambient temperature charcoal to a vacuum for prolonged periods. Maintaining a liguid nitrogen-cooled shield between the charcoal and the source of contamination prevented this degradation. A combination of bake-out and LN shielding effected recovery of degraded performance. 


\section{2 - INTRODUCTION}

Charcoal cryopump systems for fusion reactor applications were developed in this second year effort to produce high performance fusion compatible (inorganic) units for vacuum pumping helium. The first year effort (Ref 1), concentrated on evaluation of charcoal type, size and distribution, methods of charcoal attachment, and utility of inorganic bonds for charcoal retention. The results showed that a fine ( $12 \times 30 \mathrm{mesh})$, coconut PCB charcoal attached to a copper substrate with either a silver copper braze or a copper cement performed equal to or better than the same charcoal attached by organic epoxy. Epoxy bonding of charcoal is commonly used for commercial cryopump applications, but is not considered compatible for fusion reactor use.

This program continued the evaluation of compositions for charcoal retention, particularly of bonds made of brazes and low temperature inorganic cement. Brazes which might enhance wetting of the charcoal, including the successful Sil-Fos* (Silver Copper Phosphorus) braze bond from the first year program, and copper cement were prepared and tested for their ease of fabrication, durability, and performance in substrate bond charcoal assemblies.

The first year test results showed that helium pumping performanee improved with decreased charcoal particle size. Because charcoal particle sizes smaller than those tested are commercially available, this program included evaluation of a PCB coconut charcoal finer than the best performing $12 \times 30$ mesh charcoal.

The eurrent program concluded with delivery of a scaled-up charcoal pumping panel for installation in a compound pump from the vacuum system of the Los Alamos Tritium Systems Test Assembly (Ref 2). The panel, whose design was based on the results of the charcosl bond evaluation, was installed onto the compound pump's helium dewar for pre-test before shipment to Los Alamos.

The charcoal bond samples and the scaled-up panel were prepared and analyzed at Grumman. The performance test portion of the program was conducted at the Vacuum Technology Laboratory of Lawrence Livermore National Laboratory (LLNL). The expert support of W.R. Call of LLNL, T.H. Batzer, consultant to LLNL, and W.J. Poit of Grumman is gratefully acknowledged. 


\section{3- OBJECTIVE}

The overall program objective was to evaluate the helium cryosorption capability of charcoal without using organic bonds for attaching charcoal to a metal substrate. Last year's program (Ref 1), showed that high helium pumping performance is attainable with charcoal bonded to a liquid helium-cooled substrate using a braze or a copper cement. Although these bonds were shown to be superior to other methods of at tachment, they were not verified for reproducibility, durability or capability when scaled-up.

This program concentrated primarily on the characterization of brazes and cements for charcoal bonding. Samples which warranted testing were evaluated at LLNL for thermal cycle durability and helium pumping performance. The bonding agent which performed the best in a substrate bond charcoal sample was incorporated into a $16 \mathrm{in.}(40.5 \mathrm{~cm})$ diameter panel for use in a TSTA compound cryopump.

Specific program objectives were:

- Preparation of braze and cement bonded charcoal samples under controlled conditions

- Thermal cycle and performance testing of samples

- Preperation of a scaled-up charcoal bond panel for installation and testing in a TSTA compound cyropump

- Preliminary assessment of charcoal characteristics which could account for the varying performance among charcoals from different sources

- Evaluation of finer coconut charcoal grades for pumping helium. 


\section{4- EVALUATION OF BONDING AGENTS}

Prior research (Ref 1), concluded that the thermal conductivity of the bonding agent between the charcoal and the substrate exerted a strong influence on the helium pumping performance of the charcogl. In particular, a given charcoal used with bonding agents exhibiting high thermal conductivity appeared to yield the highest pumping performance. On this basis, several braze alloys and a copper cement were evaluated for compatibility with both the charcoal and the copper substrate.

These compositions are listed in Table 1 along with two samples for particle size evatuation as descrited in Subsection 4.3. The selection of Sil-FOS was based on the "self fluxing" action of the phosphorus additive while the selection of the other braze compositions was based on the Mn additive, a strong carbide former that might enhance "wetting" of the charcoal by the braze alloy.

Table 4.1 Braze Alloy Compositions Evaluated for Compatibility with Charcoul

\begin{tabular}{|c|c|c|c|c|c|}
\hline \multirow{2}{*}{$\begin{array}{l}\text { COMMERCIAL } \\
\text { DESIGNATION }\end{array}$} & \multicolumn{3}{|c|}{ COMPOSITION, WT \% } & \multirow{2}{*}{ 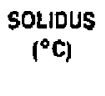 } & \multirow{2}{*}{$\begin{array}{l}\text { LLOUIDUS } \\
\left({ }^{\circ} \mathrm{C}\right)\end{array}$} \\
\hline & $\mathrm{Ag}$ & Cu & OTHER & & \\
\hline SIL-FOS & 15 & 80 & $5 P$ & 640 & 705 \\
\hline BRAZE A95 & 49 & 16 & $23 \mathrm{Zn}, 7.5 \mathrm{Mn}, 4.5 \mathrm{~N}$ & 625 & 705 \\
\hline BFAZE 852 & 85 & & $15 \mathrm{Mn}$ & 960 & 970 \\
\hline HI-TEMP 095 & & 52.5 & $9.5 \mathrm{Ni}, 38 \mathrm{Mn}$ & 880 & 925 \\
\hline 785.1418-001 & & & & & \\
\hline
\end{tabular}

To evaluate the various braze alloy compositions, a specimen of each braze alloy was placed on a $2 \times 2 \times 3 / 16$ in. $(5.1 \mathrm{~cm} \times 5.1 \mathrm{~cm} \times 0.48 \mathrm{~cm})$ copper substrate and heated in air with a propane torch. In our previous wo $k$ (Ref 1), we furnace-brazed to avoid oxidation of the braze alloy. However, the high braze temperature to which the charcoal was exposed in that process adversely affected the charcoal's pumping ability and furnacebrazing was discontinued. In the case of the brazes 495,852 and 095 , a fluxing agent was painted on the surfaces before application of the propane torch. 
With the exception of Sit-Fos braze, it wes observed that both braze alloy and copper substrate oxidized severely before melting. This condition led to poor braze ilow and poor coverage of the substrate which proved to be an inadequate base for bonding the charcoal. It was therefore decided to eliminate these brazes from further consideration.

The Sil-Fos braze alloy melted readily on the copper substrate and yielded complete coverage. It was thereby possible to sprinkle the charcoal granules on the liguid Sil-Fos braze during the heating operation and to effect their retention during the cool-down phase. This was accomplished by removing the torch from the workpiece and allowing air caoling by natural convection and conduction. The procedure usually required about 20 to 50 minutes.

Because approximately $95-98 \%$ of the effective surface area was covered with charcoal granules, the Sil-Fos braze was identified as the baseline braze bonding agent for all subsequent evaluations.

Evaluation of inorganic bonding agents centered on a copper-based cement which cures at approximately $120 \mathrm{C}(395 \mathrm{~K})$ in air and can be applied by brushing it onto the substrate. [t was identified as the baseline material for low temperature curing bonding agents. This bonding agent was previously identified (Ref 1).

The samples prepared for testing are listed in Table 2 and described in the following subsections.

Tabie 4-2 Description of Charcoal Samples

\begin{tabular}{|c|c|c|c|c|}
\hline SAMPLE : & SUESTAATE & $\begin{array}{c}\text { CHARCOAL } \\
\text { TYPE } \\
\text { PCB } \\
\text { SIEVE }\end{array}$ & BONO TYPE & $\begin{array}{c}\text { NUMBER } \\
\text { OF } \\
\text { TEST RUNS }\end{array}$ \\
\hline 100 & AL ALLOY & -325 & EPOXY & 0 \\
\hline 101 & AL ALLOY & $30 \times 140$ & EPOXY & 3 \\
\hline 102 & $V_{G} "$ COPPER & $12 \times 30$ & SIL-FOS $3 \mathrm{MHL}$ & 3 \\
\hline 103 & 'W" COPPER & $12 \times 30$ & SIL.FOS 6 MIL & 3 \\
\hline 104 & $1 / \mathrm{w}^{\prime \prime}$ COPPER & $12 \times 30$ & SIL.FOS $6 \mathrm{MIL}$ & 0 \\
\hline 105 & $1 / H^{\prime \prime}$ COPPER & $12 \times 30$ & Slt.FOS 9 MIL & 2 \\
\hline 106 & WH" COPPEA & $12 \times 30$ & SIL.FOS 9 MIL & 0 \\
\hline 107 & WH" COPPER & $12 \times 30$ & COPPER CEMENT OILUTEO & 0 \\
\hline 108 & $1 / H^{\prime \prime}$ COPPER & $12 \times 30$ & COPPEA CEMENT UNDILUTED & 0 \\
\hline 109 & W" COPPER & $12 \times 30$ & COPPER CEMENT UNDILUTED & 3 \\
\hline 110 & $w_{1+1} \cdots$ COPPER & $12 \times 30$ & SIL.FOS 6 MIL IMPROVED MFG GY USE OF DAM & 5 \\
\hline 111 & "Wh" COPPER & $12 \times 30$ & COPPEA CEMENT SLIGHTLY OILUTEO & 4 \\
\hline
\end{tabular}




\subsection{OPTIMIZATTON OF SIL-FOS BRAZE BOND}

To identify the effects of bondline thickness on charcoal helium pumping performance, 4 in. $(10.2 \mathrm{~cm})$ diameter copper substrates were prepared with three different thicknesses of braze bond layer (see Table 2). Since the braze alloy was provided in sheet form as $0.003 \mathrm{in.} \times 1.0 \mathrm{in} .(0.008 \mathrm{~cm} \times 2.54 \mathrm{~cm})$ strips, specimens were prepared using one, two and three layers of braze elloy to yield bondline thicknesses of 3,6 and 9 mils $(0.008 \mathrm{~cm}$, $0.015 \mathrm{~cm}$ and $0.023 \mathrm{~cm}$ ).

Thermal cycle and helium pumping tests were performed with the result that the char coal with the $6 \mathrm{mil}(0.015 \mathrm{~cm})$ bond layer yielded the best "overall" pumping performance, although the $3 \mathrm{mil}(0.008 \mathrm{~cm})$ band layer had behaved comparably. These tests are described in Sections 6-9. A significant reduction in pumping performance was observed with the $9 \mathrm{mil}(0.23 \mathrm{~cm})$ braze layer. This behavior appeared to be caused by the shearing off of chercoal in the thickest bond layer during cool-down with the concomitant loss of char coal on the surface.

A final sample (No. 110), was prepared which used the $6 \mathrm{mil}(0.015 \mathrm{~cm})$ braze to retain the charcoal, and which was made using the upgraded procedure described in Section 5. A retainer wall placed around the perimeter of the $4 \mathrm{in.}(10.2 \mathrm{~cm})$ diameter sample significantly improved braze and charcoal coverege. This sample produced the highest pumping performance of any braze-bonded charcoal to daie.

\subsection{OPTIMIZATION OF COPPER CEMENT BOND}

Samples were prepared which used as received copper cement (Nos. 108 and 109) and diluted copper cement, (No. 107), (see Table 2). Charcoal retention on sample No. 107 was poor and approximately $50 \%$ of the effective area was uncovered. One sample prepared with as-received cement (No. 109), indicated poorer performance than a previously pioduced specimen (Ref 1). A diluted copper cement was subsequently prepared and the resulting sample (No. 111), showed pumping performance which was slightly better than the best braze bonded sample. Based on these findings, it was decided to perform further investigations of copper cement bonded charcoal.

\subsection{OPTIMIZATION OF CHARCOAL PARTICLE SIZE DISTRIBUTION}

In the previous stujy (Ref 1 ), we showed that coconut charcoal particles exhibited belium putuping performance superior to that of other sources of activated charcoals, in addition, we showed that coconut charcoal in the finer size range (12×30 mesh), exhibited 
superior helium pumping performance to larger sized coconut charcoal. These resilts sug gest that even smaller sizes of coconut charcoal should exhibit bet ter performance. To test this hypothesis, cocunut charcoal granules in the size range $30 \times 140$ mesh and 325 mesh were bonded to a $4 \mathrm{in} .(10.2 \mathrm{~cm})$ diame:ar sluminum substrate using a silver-based epoxy adhesive. Pumping results are descrised in Section 9.

\subsection{OPTIMIZATION OF COPPER SUBBSTRATE THICKNESS}

Three thicisnesses of copper were evaluated for brazing compatibility: 0.125 in., 0.3 gs in. and $0.250 \mathrm{in}$. $0.32 \mathrm{~cm}, 0.47 \mathrm{~cm}$ and $0.64 \mathrm{~cm}\}$. Three 4 in. $(10.2 \mathrm{~cm})$ diameter brazed specimens of each thickness were prepared using Sil-Fos hraze and i $2 \times 30$ coconut charcoal. Although all three substrate thicknesses stowed excelie:t bonding of aharcoal, significent differences were observed. The $0.125 \mathrm{in.}(i .32 \mathrm{~cm})$ thick copper substrate buckled slightly during the brazing oparation, probubly due to the large non-uniform thermal stresses induced in the plate during brazing and subsequent cool-duwn. The 0.188 in. $(0.48 \mathrm{~cm})$ and the $0.250 \mathrm{in} .(0.64 \mathrm{~cm})$ thick substrates showed little evidence of buekling. However, the $0.250 \mathrm{in},(0.64 \mathrm{~cm})$ substrate required considerably greater heat input to melt the braze and bond the charcoal due to its larger mazs. On this basis, the $0.188 \mathrm{in} .(0.48 \mathrm{~cm})$ thick copper substrate was used for scale-up prosedures. 


\section{5-SCALE-UP FOR TSTA OF OPTIMIZED BONDING AGENTS}

Based on results obtained with the $4 \mathrm{in},(10.2 \mathrm{~cm})$ diameter samples described in the previous section and in Ref 1 , it was decided that the $12 \times 30$ mesh coconut (PCB) charcual granules represented the optimum for helium aryopumping and the Sil-Fos braze alloy represented the optimum bonding agent for the charcoal. Further evaluation of copper cement is recommended for future effort. All substrates consisted of $3 / 16$ in. $(0.48 \mathrm{~cm})$ thick copper plates. Because our objective was to produce a $16 \mathrm{in.}(40.6 \mathrm{~cm})$ diameter charcoal cryopanel for LLNL and TSTA, a stepwise increment in the effective area to be brazed was evaluated. Because a size limitation had not been observed during preparation of the 4 in. $(10.2 \mathrm{~cm})$ diameter panels, brazed specimens of $6 \mathrm{in} .(15.2 \mathrm{~cm})$ and $8 \mathrm{in.}(20.3 \mathrm{~cm})$ diameter were prepared. This increase represents up to a four-fold gain in the effective brazed area. Charcoal bonded specimens in these sizes were prepared using a 6 mil $(0.015$ cm) Sil-Fos braze alloy.

Although little diffjeulty was encounter ad in the preparation of a $6 \mathrm{in.}(15.2 \mathrm{~cm})$ diameter substrate, considerable difficulty was encountered in preparing the 8 in. $(20.3 \mathrm{~cm})$ diameter substrates. The braze alloy could not be maintained in the molten siate across the entire area while charging the wetted surface with charcoal. This effect was due to the inability of the brazing torch to input sufficient heat to offset the large heat losses by radiation and conduction. Thus, while the braze at the center of the disc remained molten, the braze alloy at the edges of the Gise remained unmelted.

It was concluded that a 6 in. $(15.2 \mathrm{~cm})$ diameter disc represented the largest size (i.e., 28 in. ${ }^{2}$ ) that could effectively be brazed with conventional brazing equipment. Larger sizes could be made using specifically designed brazing equipment/special fixturing to reduce heat losses during brazing.

\subsection{PREPARATION OF TSTA SPECIMEN}

It was observed, while scaling up to a 28 in. $^{2}$ substrate, that a narrow (1/8 in. $(0.32 \mathrm{~cm})$ wide) rim region near the edge of the specimen was devoid of charcoal. The braze ailoy layer was significantly thinner in this region because the braze tended to flow down the side of the disc. To compensate for this effect, a copper $30 \mathrm{mil}(0.076 \mathrm{~cm})$ sheet 
metal retainer wall was constructed that fit tightly around the specimen. Although this retainer wall was effective in reducing the loss of the braze alloy, the sil-Fos braze alloy reacted with the retainer wall and made the wall difficult to remove from the copper substrate. To reduce interaction with the braze alloy and the retainer wall, a preoxidized Kanthal A-1 strip was used as the wall material. When this alloy oxidizes, it forms an $\mathrm{Al}_{2} \mathrm{O}_{3}$ protective skin which was expected to resist wetting by the braze alloy. Figure 5-1 illustrates the Kanthal retainer wall. This approach eliminated any interaction with the braze alloy, and was effective in reducing the "edge effects" observed in the absence of the retainer wall.

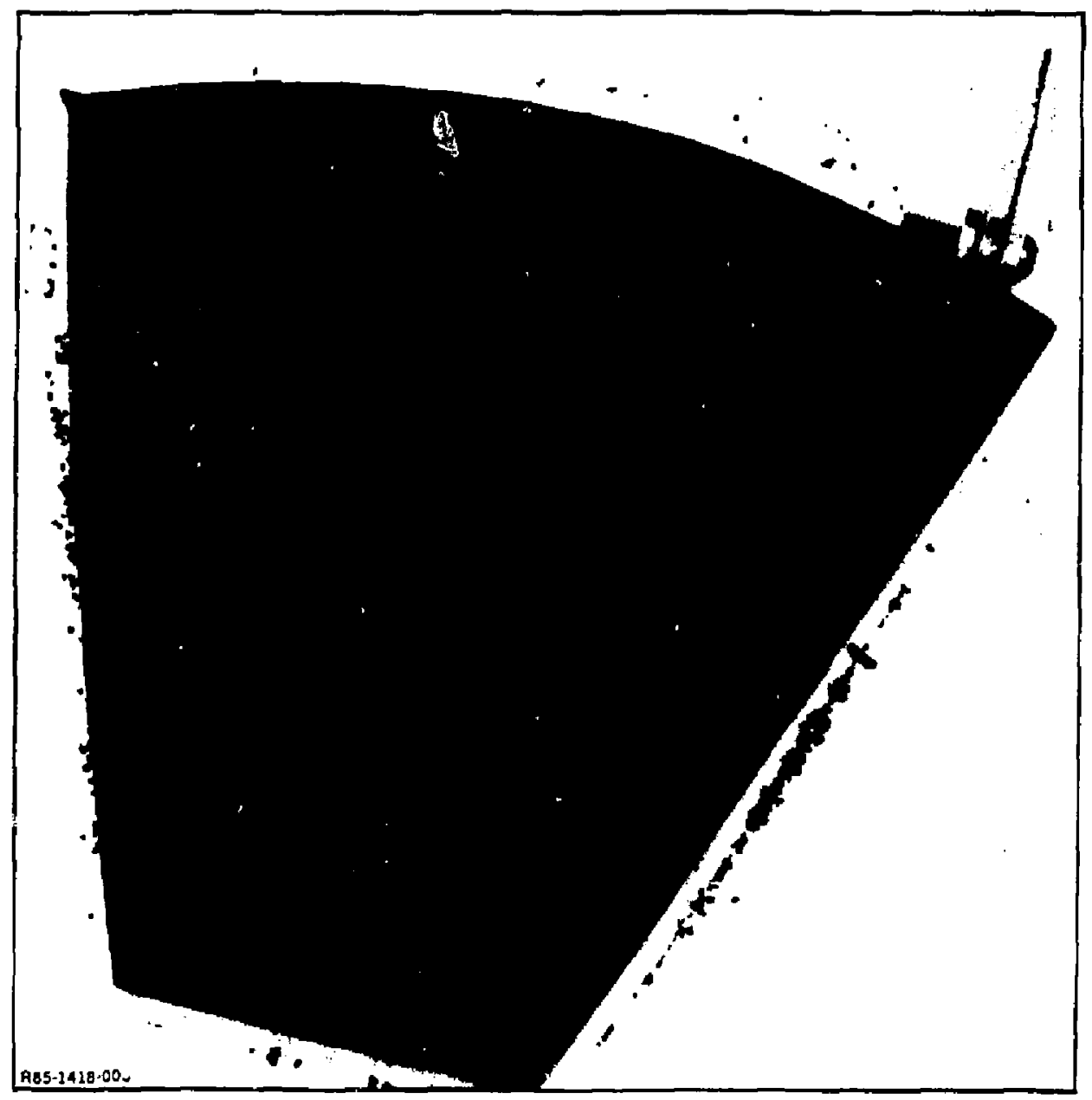

Fig. 5-1 Kanthal Retainar Shown in Plece to Retsin Charcoal During Brazing 


\subsection{DESIGN DEVELOPMENT OF 16 IN. DIAMETER TSTA TEST SPECIMEN}

In order to produce a 16 in. $(40.6 \mathrm{~cm})$ diameter panel, it was decided to subdivide the ares into a set of plates whose individuai areas dic not exceed the 28 in $^{2}\left(182 \mathrm{~cm}^{2}\right)$ limitation. Our injtial layout featured \& 6 in. $(15.2 \mathrm{~cm})$ diameter disc surrounded by eight annular plates with areas about equal to the central disc. This configuration, however, did not permit the construction of a retainer wall to confine the charcoal and braze alloy. A slight modification of this configuration was adopted in which a central octogonal piece was surrounded by eight truncated pieces fitting together to form the $16 \mathrm{in.}$ ( $40.6 \mathrm{~cm}$ ) diameter circle (see Fig. 5-2). Because machined plates required pre-drilling of attachment holes, it was necessary to fill the holes with a temporary filler to prevent the braze alloy from flow-

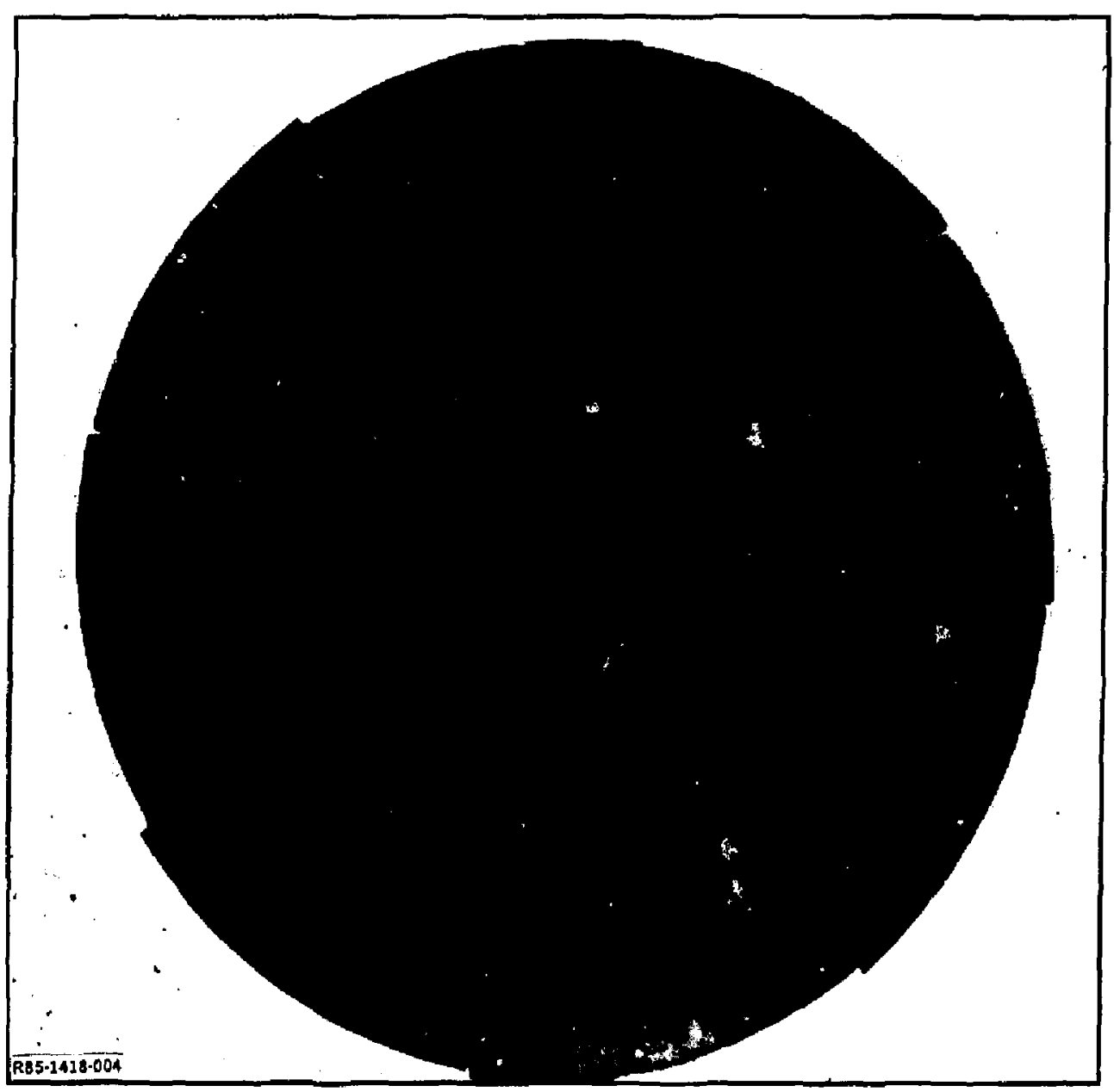

Fig. 5.2 Arrangement of Copper Piates for TSTA Pumping Panel 
ing into the holes during the brazing operation. A BN (Carborundum Corp.) filler was identified in the form of a liquid coating that can be applied and cured at $50 \mathrm{C}(325 \mathrm{~K})$ in air. It was founa that the $\mathrm{BN}$ filler was effective in preventing braze flow into the predrilled holes and was easily removed after the brazing operation.

Using the pre-formed Kanthal A-1 retainer, a 16 in. $(40.5 \mathrm{~cm})$ diameter charcoal cryopump panel (Fig. 5-3) was fabricated from a central octagonal piece plus eight annular pieces using 0.188 in. $(0.4 \mathrm{~B} \mathrm{~cm})$ thick copper tiles, $12 \times 30$ mesh coconut charcoal granules and Sil-Fos braze alloy.

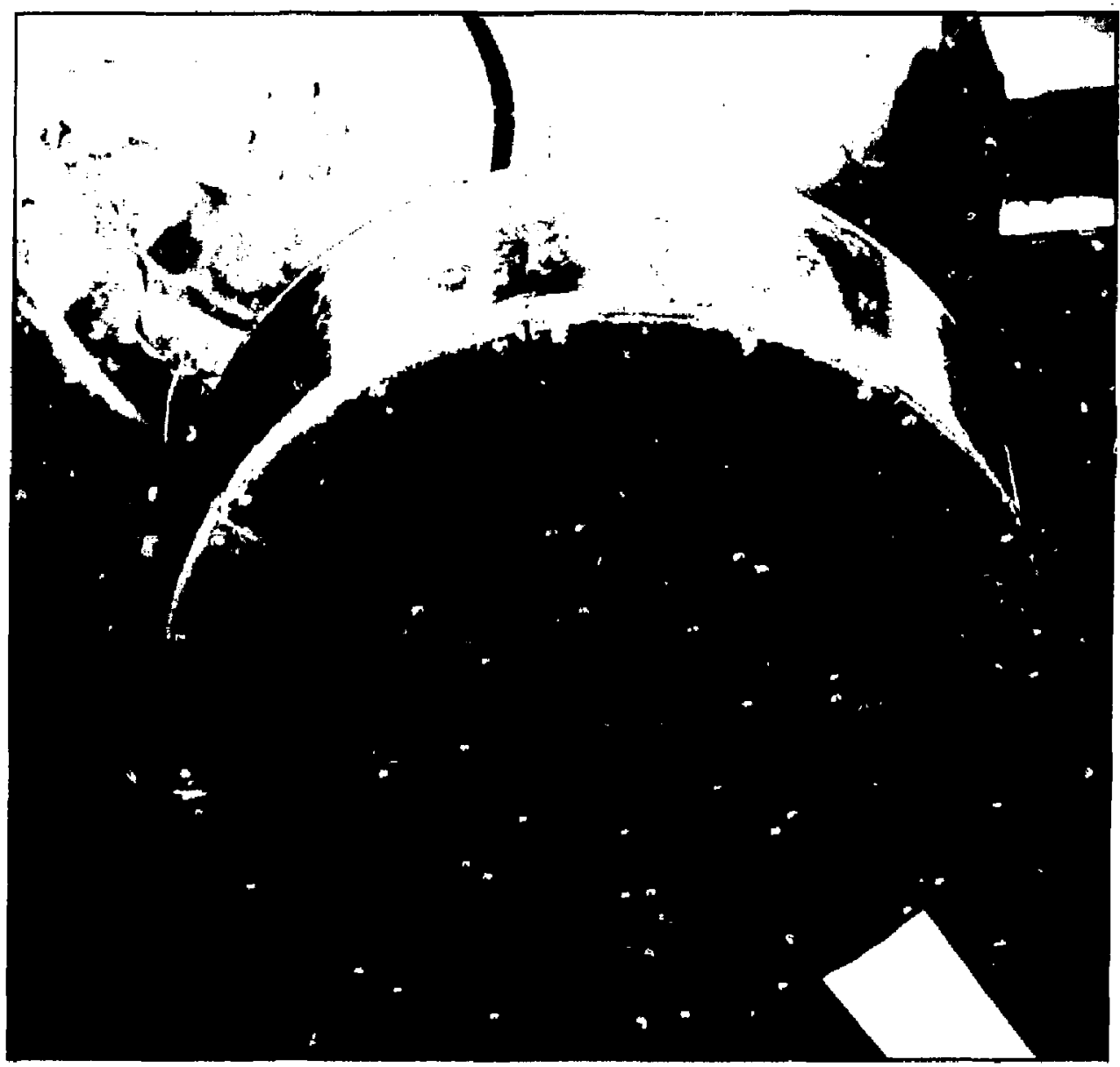

Fig. 94 Hefium Pumping Performance of Coconut Charcoal Bonded with Undiluted Copper Cement 


\section{6 - TEST PROGRAM}

The test program consisted of three parts. The first part continued an evaluation (see Ref 1), to determine the optimum charcoal particle size for pumping helium. The Ref 1 results had shown increased pumping capability with decreased particle size, so the first part of the test program evaluated finer particle sizes than those previously tested.

In the second part, charcoal test samples which featured either a braze or a copper cement to attach the charcoal to copper substrates, were subjected to performance and thermal cycle tests. Performance tests pexformed on the samples in their "as received" conditions were repeated following exposure to various environmental conditions.

The third part evaluatec performance and integrity of the $16 \mathrm{in.}(40.6 \mathrm{~cm})$ diameter sharcoal pumping papel installed on the helium dewar of the TSTA charcoal compound cryopump.

Performance comparisons - either between repeated test runs on a given sample or between runs on different samples-were based on measurement of specific pumping speed versus specific capacity for a constant helium throughput. 
The vacuum test installation at the LLNL Vacuum Technology Laboratory, which was used for the 1983 program (Ref 1) was used for this program. The charcoal test articles were configured either as $4 \mathrm{in}$. $(10.2 \mathrm{~cm})$ diameter samples or as segruents of the $16 \mathrm{in}$. $(40.6 \mathrm{~cm}$ ) diameter panel for the TSTA pump. The exposed size of the $10.2 \mathrm{~cm}$ samples was 3.5 in. $(8.9 \mathrm{~cm})$ diameter. The former were installed on a test pump appended to the main test tank, and the latter were mounted on the TSTA pump heliun dewar installed in the main tank. The test equipment is deseribed in the following subsections.

\subsection{TEST APPARATUS}

The system used in the study is illustrated in Fig. 7-1. The roots/mechanical system roughed the main chamber and the test pump, while a turbo-molecular pump provided final roughing to a pressure in the $10^{-7}$ range prior to introduction of liguid helium. Liguid nitrogen in the eryopump shield dewar or in the main tank shield contributed to the pumpjown. In some tests, when the turbo-molecular pump was unavailable, the liquid nitrogen units performed final roughing. A shield in the main tank was installed for the TSTA panel tests only.

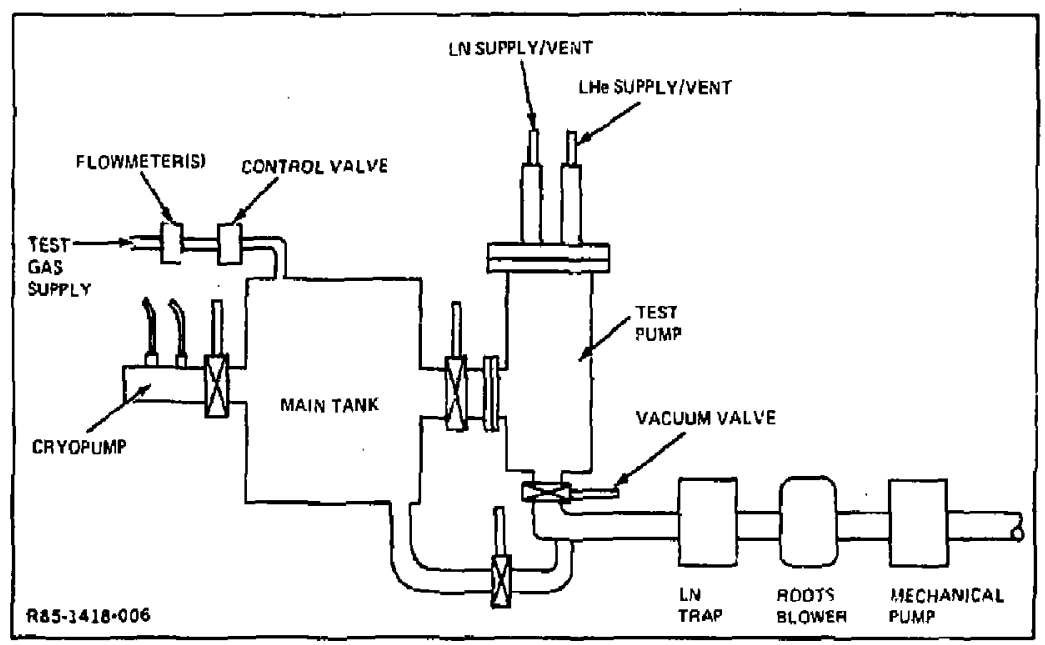

Fig. 7-1 Test System Schematic 
The test gas helium feo into the main chamber was controlled by a servo-operated valve and shut-off valve. Flow for the $4 \mathrm{in} .(10.2 \mathrm{~cm}$; panel tesis was held at a constant value of $6 \times 10^{-4}$, Torr liter $\mathrm{s}^{-1} \mathrm{~cm}^{-2}$, within a range of $\pm 4 \%$. This value is representative of fusion reactor throughput rates. For the $16 \mathrm{in} .(40.6 \mathrm{~cm})$ panel tests the flow was $6 \times 10^{-4}$ Torr liter $\mathrm{s}^{-1} \mathrm{~cm}^{-2}$, or $3 \times 10^{-4}$ Torr liter $\mathrm{s}^{-1} \mathrm{~cm}^{-2}$.

\subsection{TEST PUMP}

The workhorse pump used in the Ref 1 tests was agkin the test bed for the $4 \mathrm{in}$. $(10.2 \mathrm{~cm}$ ) panel evaluations (Fig. 7-2 and 7-3). The pump's liguid helium reservoir which held the test panel was shielded by a fcur-sided chevron array. Access to the panel was through a demountable bottom plate which sompleted the shielding.

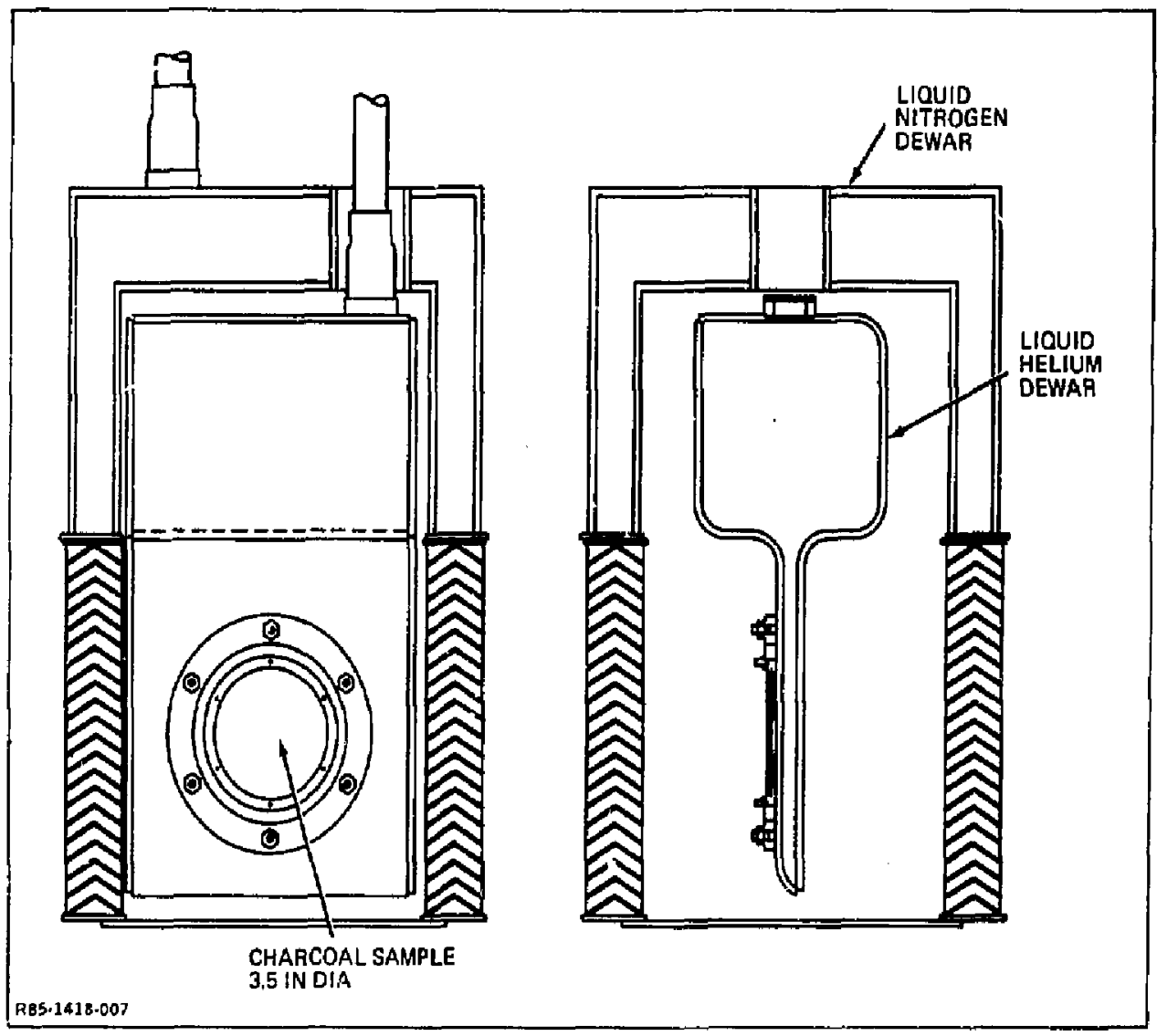

Fig. 7-2 Workhorse Cryopump for Charcoal Sorbent Terts 


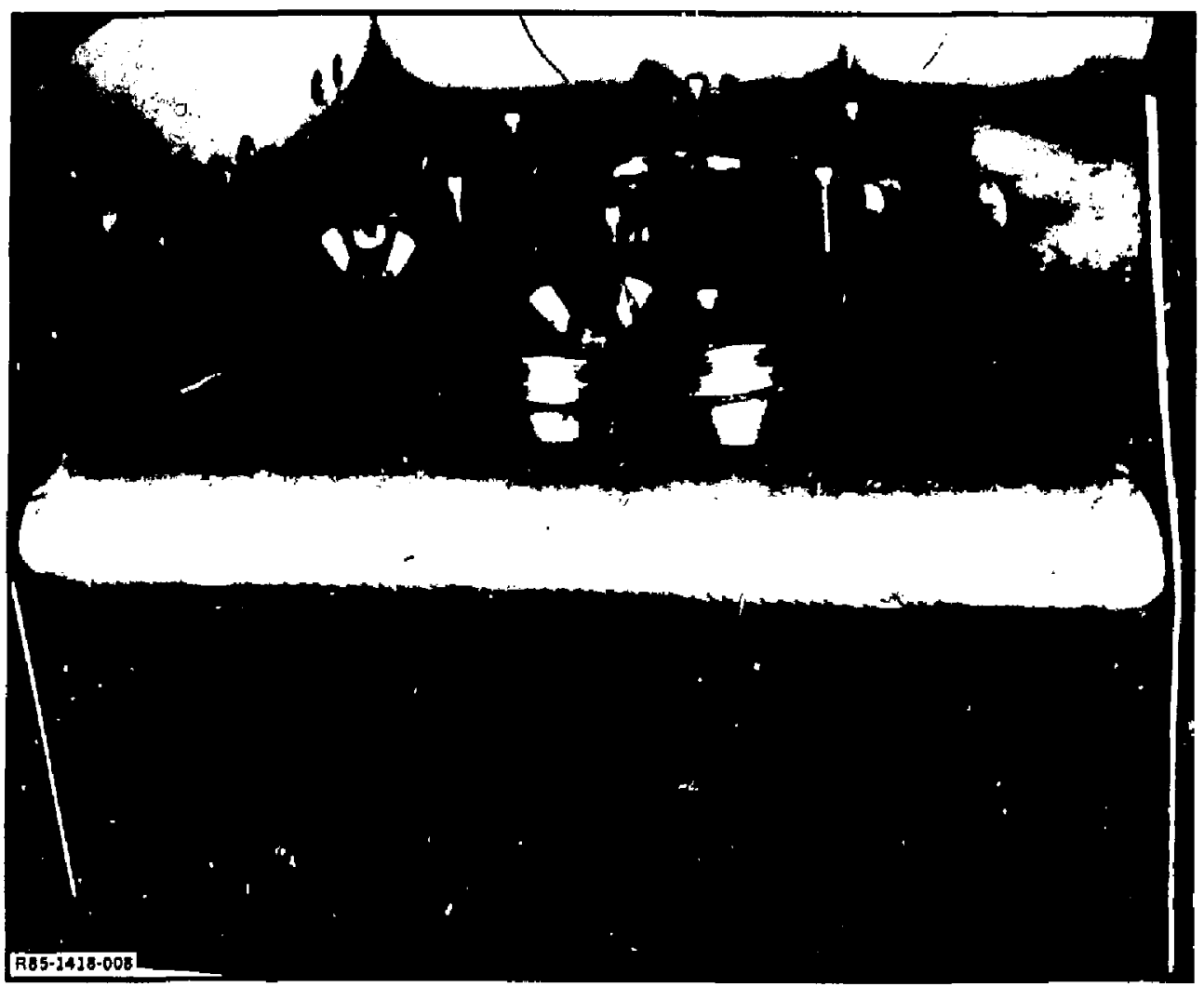

Fig 7.3 Charcosl Panel Intalled in Workhora Cryopump

\subsection{TEST DEWAR}

For the 16 in. $(40.6 \mathrm{~cm})$ panel tests, the parsl was mounted on the liquid helium dewar of a TSTA compound cryopump (Ref 3). Los Alamos personnel had disassembled the cryopump, removed the existing pumping panel and shipped only the dewar to LLNL for preliminary evaluation of the charcoal panel. When the dewar is in the compound cryopump, it is surrounded ty a liquid helium-cooled inner shield and chevron and a liquid nitrogen cooled outer shield and chevron (Fig. 7-4). In the test cell at LLNL, the helium dewar was suspender in the main test tank, surrounded by the liquid nitrogen-cooled shield mounted inside the tank wall (Fig. 7-5). 


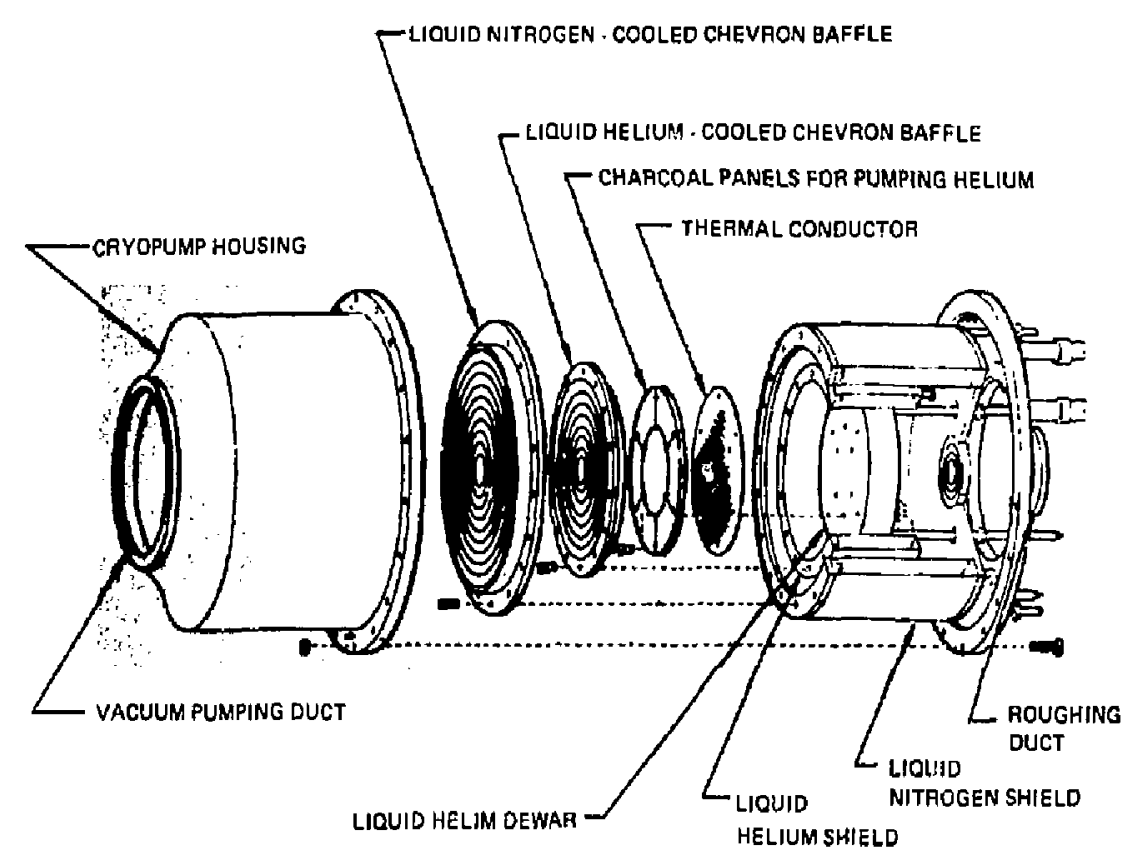

R85-1418-009

Fig. 7.4 Charcoal Compound Cryopump

\subsection{TEET ARTICLE}

Three types of test articles were used for the three parts of the test program cited in Subsection 7.3. For the evaluation of charcoal particle size, two samples were prepared. The samples were 4 in. $(10.2 \mathrm{~cm})$ diameter aluminum alloy plates with fine $30 \times 140$ mesh or $<325$ mesh charcoal attached by a thin layer of epoxy.

For the performance and thermal cycle tests, the charcoal (12x30 mesh) was attached to 4 in. $(10.2 \mathrm{~cm})$ diameter copper plates using either braze alloy or copper cement.

Each aluminum or copper plate was held by a retainer ring against the test pump's liquid helium dewar, with a copper mesh between the plate and the dewar to enhance thermal conductance.

For evaluation of the scaled-up $16 \mathrm{in} .(40,6 \mathrm{~cm})$ dianeter charcoal test panel, the charcoal ( $12 \times 30$ mesh) was brazed to $3 / 16 \mathrm{in.}(0.48 \mathrm{~cm})$ thick copper plate. The test panel's nine pieces (Fig. 5-3) were mechanically attached to the helium dewar's flat lower sur face, with a copper mesh between the panel and the dewar to effect good thermal contract. 


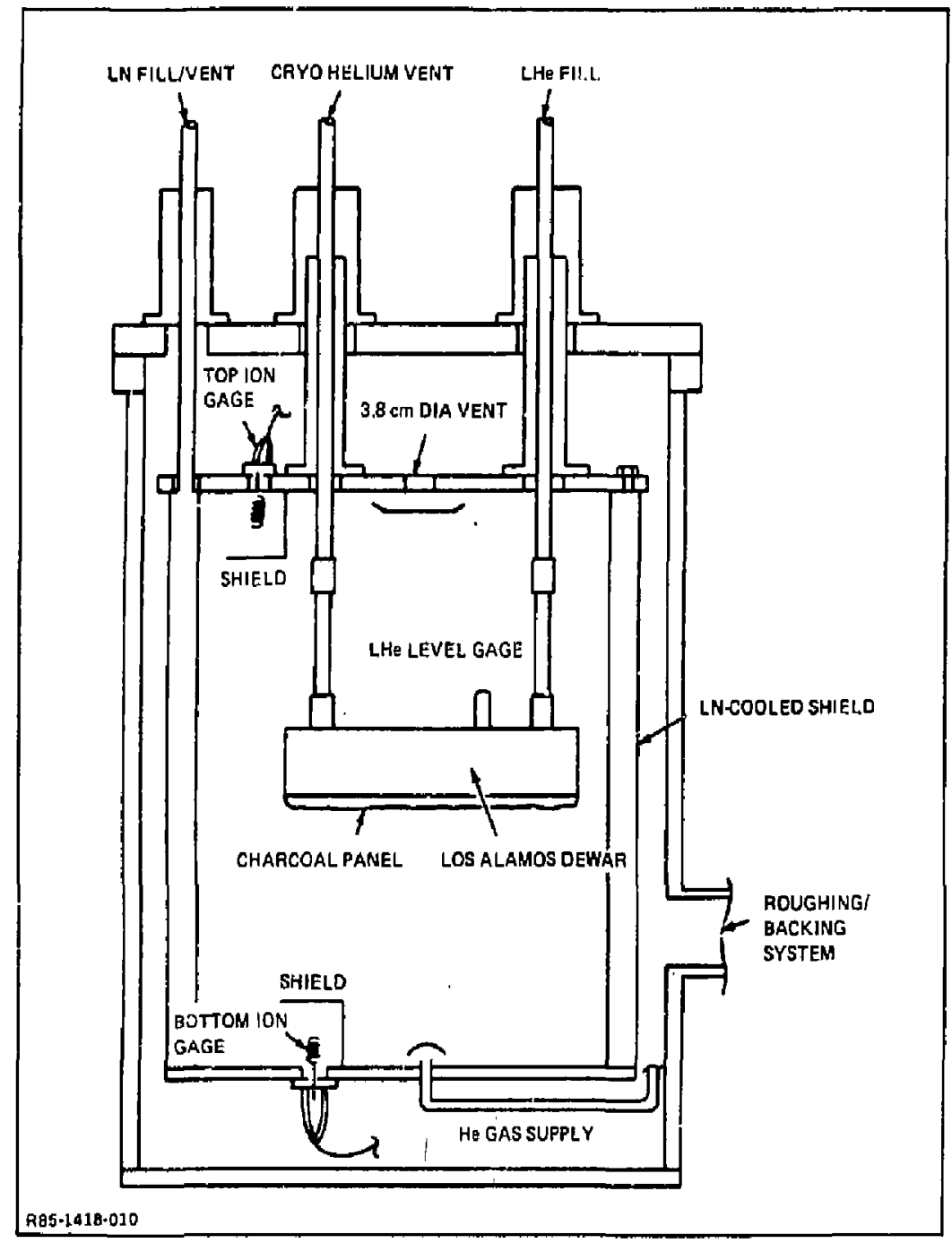

Fig 7.5 TSTA Dewar in the LLNL Vacuum Chamber

\subsection{INSTRUMENTATION}

Temperature, pressure and flow measuring instruments monitored the condition of the test articles and apparatus and provided data. Silicon diode sensors measured the temperature of the charcoal panels, the test pump helium dewar, the TSTA pump dewar, the test pump chevron and the main tank LN shield. The sensors were calibrated in liquid nitrogen or helium before the test program began. Nude ionization gages measured pressure in the main tark, at the bottom and top of the appended test pump container in the interspace out- 
side the test pump's chevron baffles, and at the top and bottom of the volume formed by the LN shield in the main tank. The gages' relative sensitivity to helium was 0.143 based on manufacturer's data. A digital flow meter celibrated for air indicated gas flow into the test tank. The meter was calibrated in the laboratory for helium and the relative sensitivity for helium was 0.714 . 


\section{8 - TEST METHOD}

The test apparatus shown in Fig. 7-1 was used for the 4 in. $(10.2 \mathrm{~cm})$ diameter sample tests and for the $16 \mathrm{in} .(40.6 \mathrm{~cm})$ diameter pe iel test. Procedures are described for testing both types.

\subsection{TESTING OF 4 IN. (10.2 CM) SAMPLES}

The first semple was installed with the test tank up to air with the isolation valve between the tank and the appended test pump open. For subsequent installations, the main iank remaitıed under vacuum. The $\mathrm{LN}$-trapped roots/mechanical pump roughed the tank and pump. After ten minutes of roughing, the turbo-molecular pump isolation valve was opened and the roots/mechanical system was isolated. If test sample bakeout was specified, it was performed 20 minutes after roughing began by passing heated air for 20 minutes through the cryopump's helium dewar. At the end of bakeout (or when tank pressure indicated less than $5 \times 10^{-5}$ Tolr without bakeout), cooldown of the test pump's chevrons and shield with LN began. Liquid helium cooldown of the pump dewar began when the chevron temperature had dropped to $95^{\circ} \mathrm{K}$, which occurred approximately $75 \mathrm{~min}$ after the start of chevron cooldown without bake, or 90 min with bake. At this time, tank pressure was on the order of $5 \times 10^{-7}$ Torr.

Approximately one hour after the start of liquid helium transfer, the sample temperature stabilized and the helium test gas was fed into the main tank. The total elapsed time from the start of roughing until temperature stabilization was approximately 170 min without bakeout and 210 min with bakeout. Flow was increased until the steady state value was achieved, usually in less than two minutes when the accumulated helium on the sample was less than 0.07 Torr liter $\mathrm{cm}^{-2}$.

Multiple test runs were made on some individual samples to evaluate the effect of prior conditions on the sample's performance. Therefore, the rough-down and cooldown sequences differed from the initial conditioning described above. These sequences are discussed as part of the test results (see Section 9 ).

Pressure (nitrogen equivalent), temperature and helium gas flow (air equivalent) were recorded at appropriate intervals during each test run. In addition, a strip chart recorded 
pressure for run diagnostics. Pump and tank pressures were also recorded 5 to 10 minutes after the termination of helium gas flow at the end of a run.

\subsection{TESTING QF 16 IN. (40.6 CM) DIAMETER PANEL}

The TSTA pump dewar with the charcoal panel attached was installed in the liquid nitrogen shield. This assembly, was then suspended from the test apparatus cover, and placed in the main chamber (Fig. 7-5). The appended pump remained under yacuum throughout this test series but was not couled down and did not function as a pump. The roots/mechanical system and turbo-molecular pump roughed the apparatus. The pump dewar was baked at $330^{\circ} \mathrm{K}$ for over one hour with the shield cooled, prior to introduction of the liquid helium. Data recording for this test was similar to that described above. 


\section{9 - TEST RESULTS}

Pumping speed as a function of pumping capacity was determined for all samples that were testef. The test procedure for determining pumping speed was to use the constant flow method by introducing a fixed flow of helium ges into the main tank for the duration of a run. This flow was continued until a minirnum of 20 min run time had elapsed. Because fusion reactor uryopumps will probably be regenerated after run periods of less than $20 \mathrm{~min}$ to minimize tritjum inventory, data taken before $20 \mathrm{~min}$ elapsed time is of most interest.

Helium specific pumping speed $\mathrm{s}_{\mathrm{S}}$ in liter $\mathrm{s}^{-1} \mathrm{~cm}^{-2}$ was determined from the relationship:

$$
s_{S}=2.61 \times 10^{-3} \times Q i /(P i A)
$$

Here, $A$ is the charcoal sorbent effective surface aree in $\mathrm{cm}^{2}, Q \mathrm{i}$ is the indicated helium flow in scem (air), and $\mathrm{Pi}$ is the ionization gage pressure in Torr (indicated for nitrogen). The charcoal sorbent effective surface area for the $4 \mathrm{in} .(10.2 \mathrm{~cm})$ diameter panels was $9.3 \mathrm{in}^{2}\left(60.1 \mathrm{~cm}^{2}\right)$, and for the 16 in. $(40.6 \mathrm{~cm})$ diameter panel, it was 189 in. $^{2}\left(1221 \mathrm{~cm}^{2}\right)$. The pressure Pi for the small sample tests was measured by the ionization gege at the top of the appended pump cavity in the volume between the pump housing and the pump's nitrogen cooled shield. The pressure Pi for the larpe panel tests was measured by the top ionization gage shown in Fig. 7-5. i. isum specific capacity $\mathrm{C}_{\mathrm{S}}$ in Torr liter $\mathrm{cm}^{-2}$ was determined from:

$$
\mathrm{C}_{\mathrm{S}}=1.09 \times \mathrm{V}_{\mathrm{i}} / \mathrm{A}
$$

where $\mathrm{V}_{\mathrm{i}}$ is the cumulative volume of helium in sce (air).

\subsection{EVALUATION OF CHARCOAL PARTICLE SIZE}

A set of runs was included in this program to determine the performance of finer (30x140 mesh and < 325 mesh) PCB coconut charcoal than had been eva!uated in the preceding program (Ref 1). The smallest mesh size charcogl (12×30) in that program had produced the highest puraping speed. The $30 \times 140$ mesh aharcoal sampie (No. 101), was tested in its as received condition (twn runs) and in its condition following a $340 \mathrm{~K}$ vacuum bake (one run). 
All runs were terminated in less than $10 \mathrm{~min}$, as pressure rose excessively with the $6 \times 10^{-4}$ Torr liter s $\mathrm{cm}^{-2}$ helium flow. The quantity of $30 \times 140$ mesh PCB charcoal per $\mathrm{sq} \mathrm{cm}$ of panel surface area is insufficient to absorb the helium at the test flow rate. Consequently, the finer mesh (<325) charcoal (No. 100), was not tested. The best performing charcoal cited in Ref 1 (12x30 mesh PCB), is evidently the optimum charcoal particle size for helium cryopumping.

\subsection{THERMAL CYCLE TESTS}

These tests were performed to evaluate the integrity of charcoal/bond combinations after being subjected to temperature variations and to helium absorption and regeneration. The profiles were representative of conditions to be expected in operation. In general, the samples were cooled from ambient temperature to liquid helium temperatures as described in Section 8. Following a period of helium pumping (more then $20 \mathrm{~min}$ ), the pump dewar was warmed to $85-90^{\circ} \mathrm{K}$. The sample temperature reached $45-50 \mathrm{~K}$. This warming operation effected sample regeneration; belium evolved quickly from the sample when the sample tem* perature was in the $18-25^{\circ} \mathrm{K}$ range. The sample was then recooled to the liquid helium temperature range and helium pumping was repeated. These helium pumping periods were performed three times on each sample except for one case in which poor performance would have made a third run unproductive.

Eight samples were prepared for the thermal eyele tests (șee Table 2). Five used braze ior attaching the charcoal to the copper substrate, comprising one $3 \mathrm{mil}(0.008 \mathrm{~cm})$ thick braze sample, two $6 \mathrm{mil}(0.015 \mathrm{~cm})$ braze samples, and two $9 \mathrm{mil}(0.023 \mathrm{~cm})$ braze samples. One sample of each braze thickness was tested. Three samples consisted of copper cement: two cements were applied in the as-received form and one was applied in a diluted form. One of the as-received cement samples was selected for test. The diluted cement failed to retain the charcoal; that sample was therefore discarded prior to testing.

All tested samples satisfactorily completed the thermal cycle tests. The charcoal ramained bonded after the cycles. For tests in which the repeated pumping was done on a single day (Fig. 8-1 to 9-4), the pumping performance was consistent from one run to the next. The pumping performance, as indicated by the specific speed for helium, was considerably lower for the chareoal bonded by $9 \mathrm{mil}(0.023 \mathrm{~cm})$ thick braze (No. 105), than for the samples with thinner braze bonds (Nos. 102 and 103). For this reason, the third performance run on the $9 \mathrm{mil}(0.023 \mathrm{~cm})$ sample was omitted. The charcoal sample attached by undiluted copper cement (Fig. 9-4), yielded lower performance and the formulation was subsequently changed (sample No. 111), for later tests. 


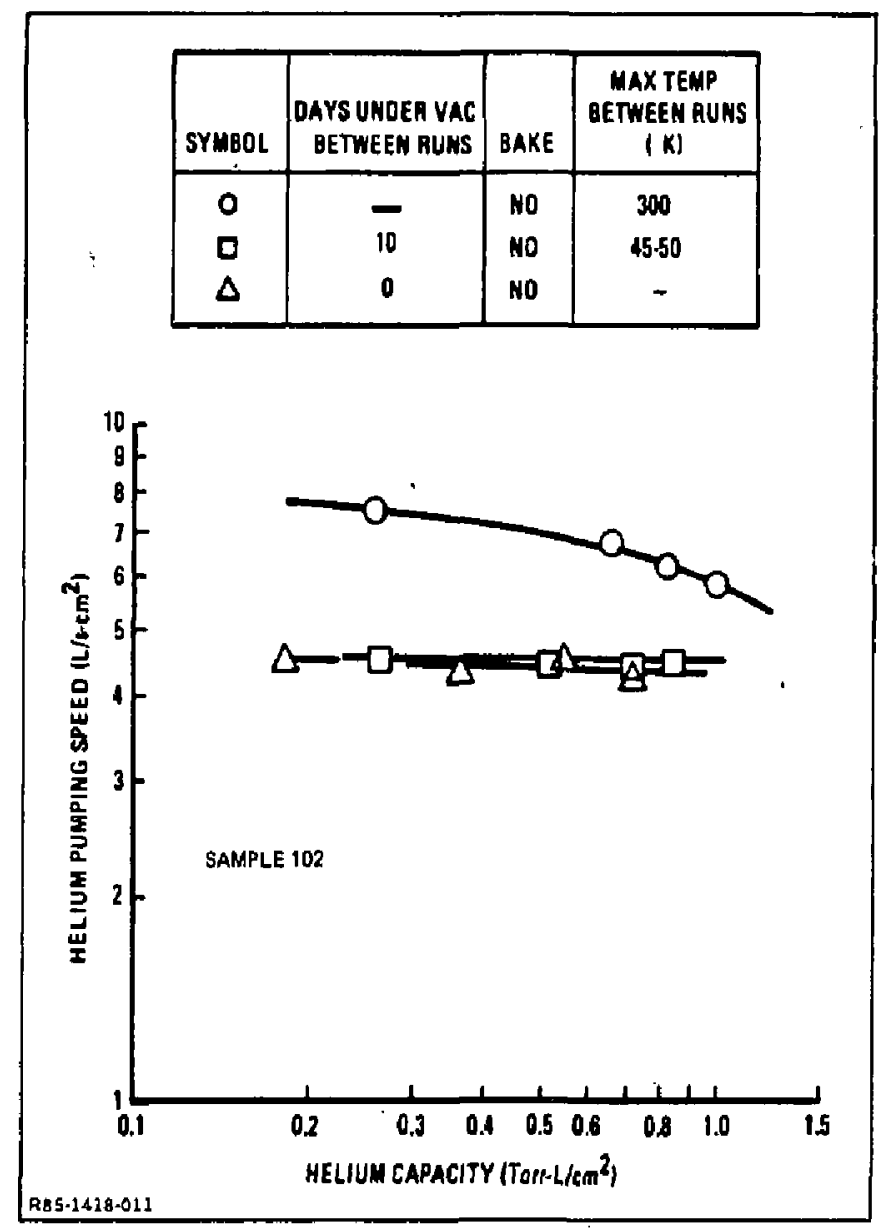

Fig. 9.1 Helium Pumping Pertormance of Coconut Charcosl Bonded with 3-Mil Sil-Fos Braze

For the sample having a $3 \mathrm{mil}(0.00 \mathrm{~B} \mathrm{~cm})$ thick braze bond (No. 102) a ten day lapse occurred between the first and second runs. The second and third runs were made on one day. The pumping performance of these two runs was practically identical. However, it was measurably lower than that of the first run (see Fig. 9-1).

During the ten day lapse, the sample cemained attached to the cryopump dewar in the test system. The liquid helium and nitrogen source was cut off and the sample gradually warmed to ambient temperature. The test system held under passive vacuum for the ten days before the roots/mechanical pumps were run and cryogens re-introduced for the second helium pumping run. 


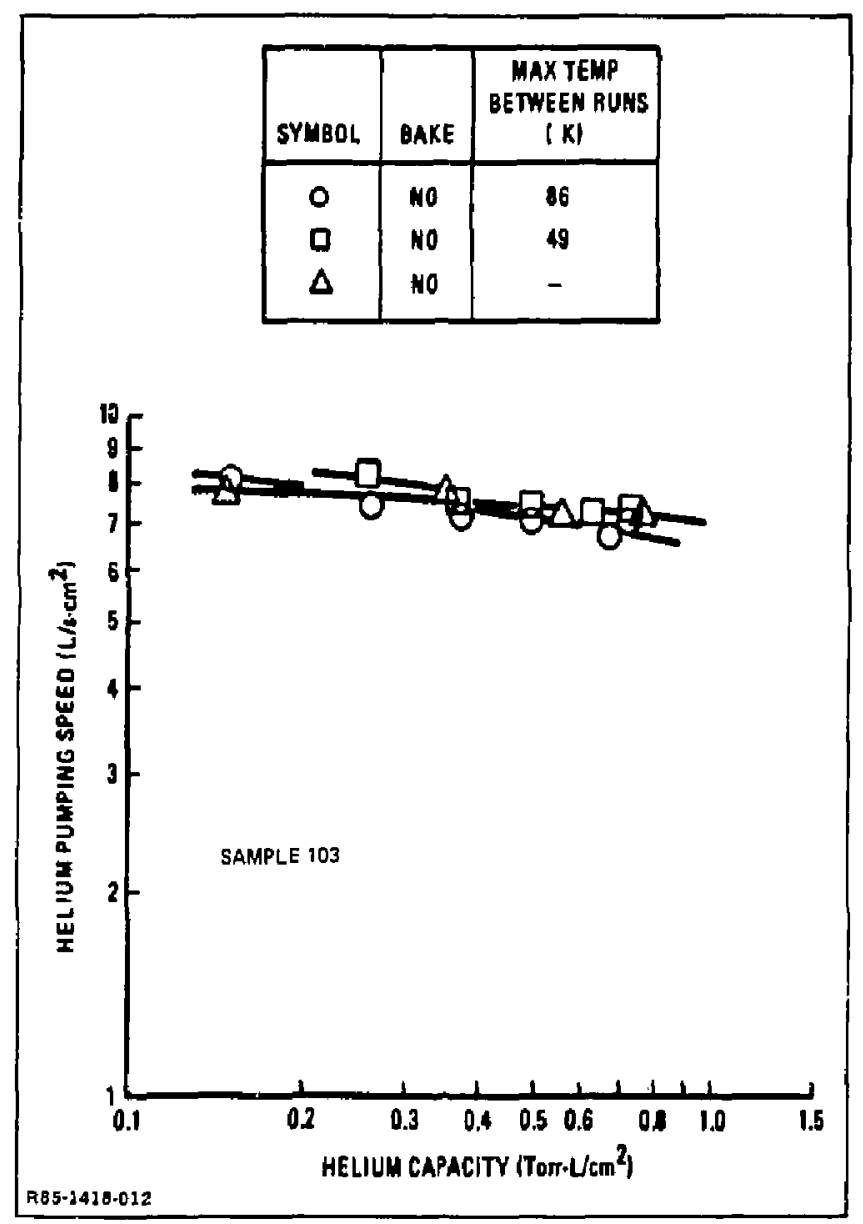

Fig. 9-2 Helium Pumping Performance of Coconut Charcoal with 6.Mil Sil-Fos Braze

It was observed that the charcoal panel's helium pumping performance was adversely affected by this exposure over a prolonged period to the vacuum chamber environment. As a result, an additional test series was included in the program to observe the effect of different conditions on the helium pumping performance.

\subsection{ENVIRONMENTAL TESTS}

Two semples were prepared for evaluation of pumping speed and capacity after exposure to conditions including warmup, exposure to air, bake-out and prolonged vacuum. Sample Nos. 110 and 111 were similarly configured to those بvaluated in the Thermal Cycle 


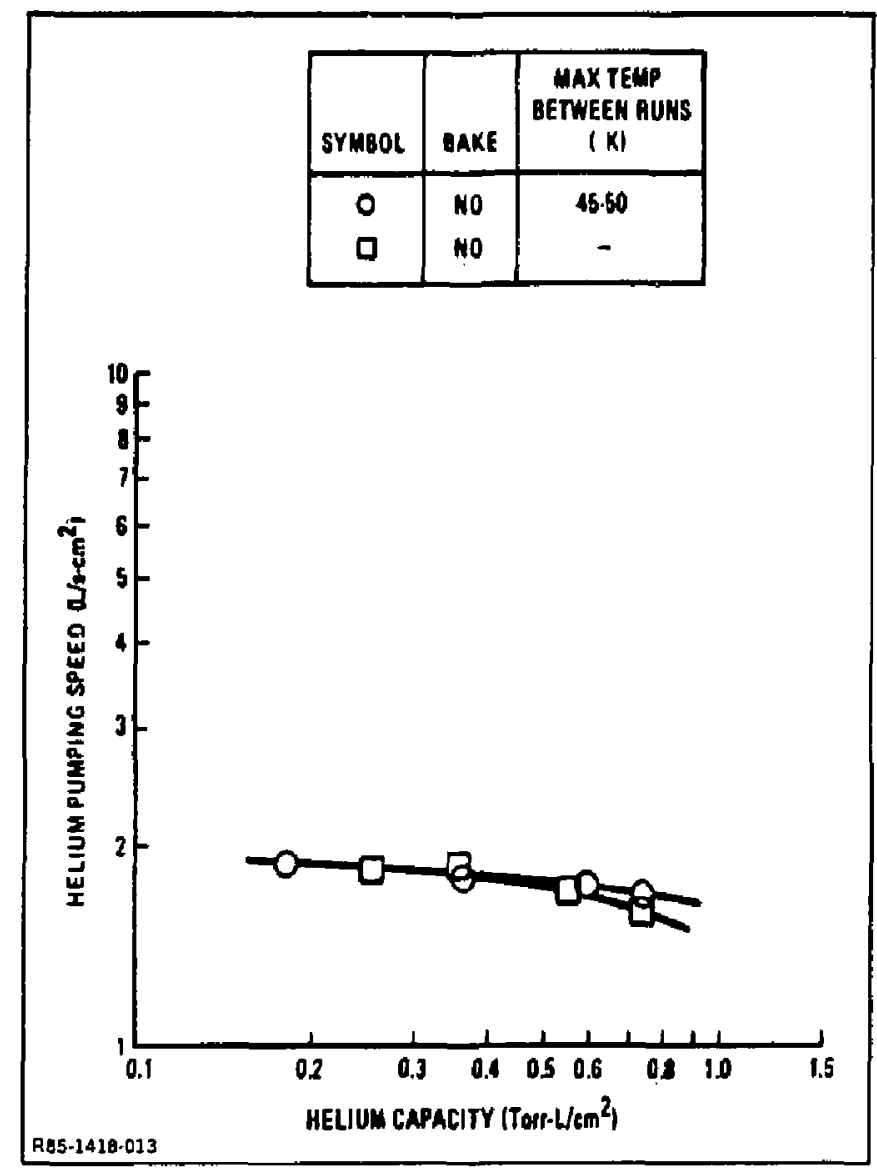

Fig. 9-3 Helium Pumping Performance of Coconut Chartod Bonded vith 9-Ail Sil-Fos Braze Lyer

Tests, and comprised $12 \times 30$ mesh PCB coconut charcoal bonded to a copper substrate with either braze or copper cement. These samples were the result of improved fabrication techniques and had better charcoal retention than had been previousiy obtained.

Each sample in its as received condition was installed in the vacuum system and cooled down in accordance with the previously outlined procedure. Helium throughput was nominally beld at a $6 \times 10^{-4}$ Torr liter s $\mathrm{s}^{-1} \mathrm{~cm}^{-2}$ for all runs. 


\begin{tabular}{|c|c|c|}
\hline SYMBOL & BAKE & $\begin{array}{c}\text { MAX TEMP } \\
\text { BETWEEK RUMS } \\
\text { (K) }\end{array}$ \\
\hline$O$ & NO & 4 \\
$\square$ & NO & 38 \\
$\Delta$ & NO & - \\
\hline
\end{tabular}

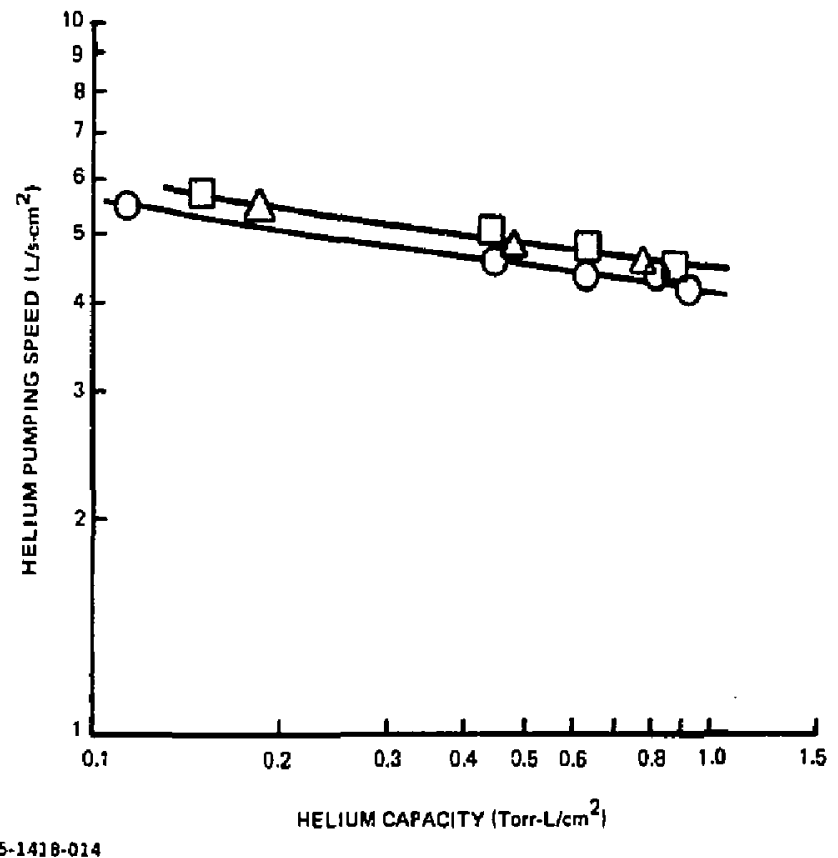

- SAMPLE NO. 109

R85-14] B-014

Fig. 9-4 Helium Pumping Performance of Coconut Charcoal Bonded with Undiluted Copper Cement

\subsubsection{Charcoal Sample with Braze Bond (No. 110)}

Five helium pumping runs were made with this sample. Figure 9-5 shows a measurable variation in helium pumping speed from over 10 liter $s^{-1} \mathrm{~cm}^{-2}$ to under 8 liter s $\mathrm{s}^{-1} \mathrm{~cm}^{-2}$.

The best performance was obtained with the as-received sample tested in its unbaked condition. Specific pumping speed remained over 10 liters ${ }^{-1} \mathrm{~cm}^{-2}$ after more than $20 \mathrm{~min}$ of pumping at a pumping capacity of approximately 0.7 Torr liter $\mathrm{cm}^{-2}$ absorbed helium. 


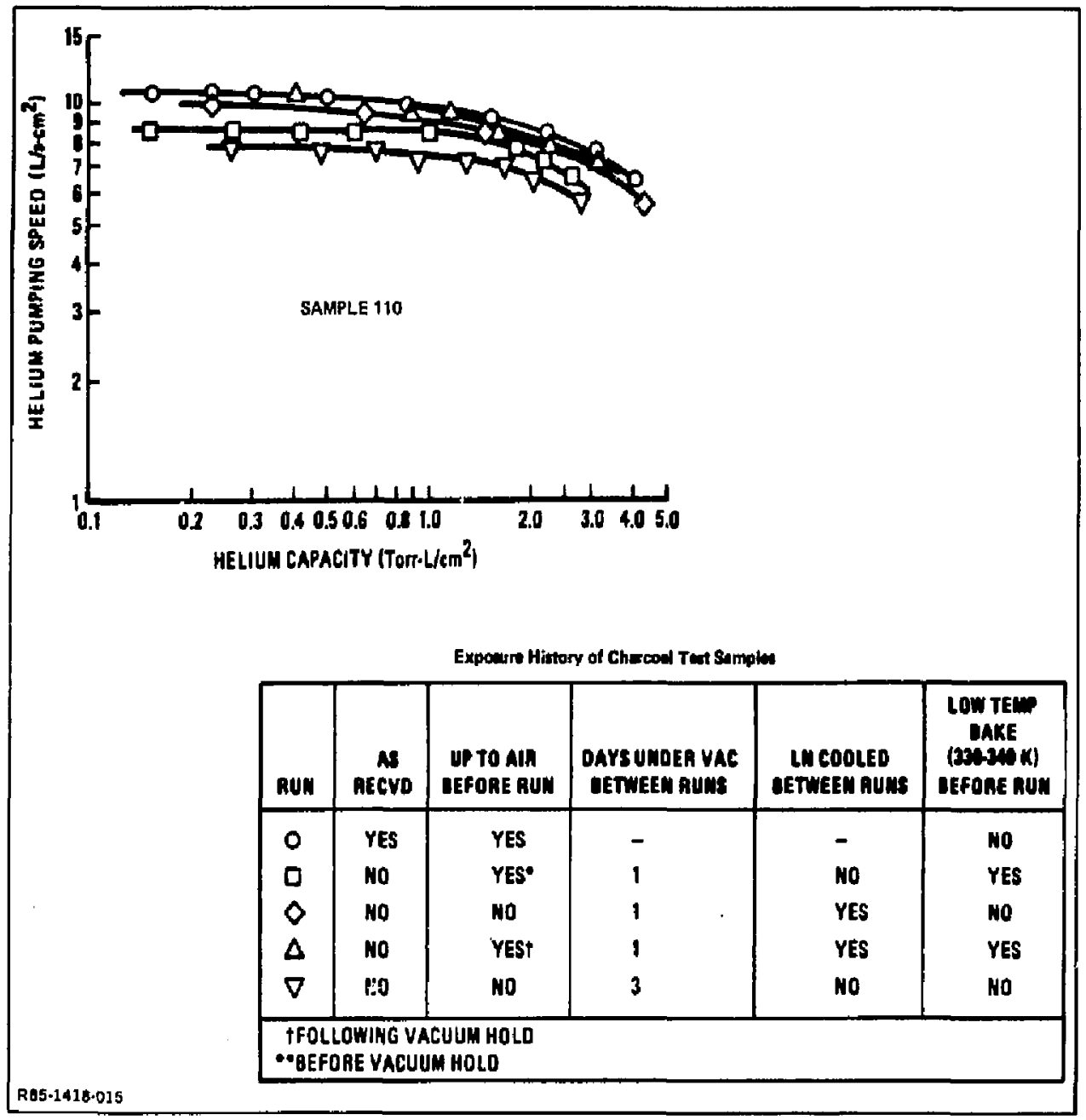

Fip. 9-5 Effect of Vacuum Exposure History on Helium Pumping Performance of Coconut Charcoal Bonded by 6-Mil Sil-Fos Brazo

After the first run, the sample was warmed up, then held under vacuum overnight. The chamber was brought up to air for less than an hour before it was roughed down. The sample was vacuum baked at $330^{\circ} \mathrm{K}$ for $30 \mathrm{~min}$ before being re-cooled. Pumping performance during the second run showed a drop to under $91 \mathrm{~s}^{-1} \mathrm{~cm}^{-2}$ helium pumping speed. 
During the 16 hr period between the second and third runs, the ciyopump's liquid helium dewar was emptied, but liquid nitrogen continued to cool the chevron shield. The helium dewar temperature did not exceed $95^{\circ} \mathrm{K}$. Vacuum was continuously maintained and the sample was not baked before the third run. Pumping performance recovered to over 10 liter $\mathrm{s}^{-1} \mathrm{~cm}^{-2}$ at low capacity and was over 9 liter $\mathrm{s}^{-1} \mathrm{~cm}^{-2}$ after $20 \mathrm{~min}$ of steady state pumping.

The vacuum chamber was brought up to air following the third run, after which the vacuum was re-established and the pump chevrons cooled down for an overnight hold. The sample was vacuum baked at $330^{\circ} \mathrm{K}$ before liquid helium cooling. The high helium pumping performance of the first run was repeated in the fourth run.

Following the fourth run the cryogens were purged and the pump warmed up while vacuum was maintained in the system for three days. The pump was then cooled without sample bakeout and the ensuing run showed the poorest performance of all runs with a helium pumping speed of 8 liter $\mathrm{s}^{-1} \mathrm{em}^{-2}$ throughout the run. Although this performance was low compared to other results for this sample, it was considered a good performance compared to results obtained in Ref 1.

\subsubsection{Charcoal Sample with Cement Bond (No. 111)}

This sample was exposed to four helium pumping runs (Fig. 9-6). The first run after sample installation yielded the highest helium pumping speeds. The sample was kept under vacuum in the chember for the 28 day duration of the tests.

The as received sample was vacuum baked at $330^{\circ} \mathrm{K}$ before cooldown. The measured helium pumping speeds were above 11 liter $\mathrm{s}^{-1} \mathrm{em}^{-2}$ until $20 \mathrm{~min}$ of steady state throughput had been absorbed by the charcoal.

The cryogens were purged out of the test pump after the first run, which warmed up and remained at ambient temperature under vacuum for five days before being baked at

$330^{\circ} \mathrm{K}$. Pumping performance in the second run, dropped below 7.5 liter s $\mathrm{er}^{-2}$ after $20 \mathrm{~min}$ of pumpinr.

The cryogeris were purged and the pump allowed to warm up gradually to ambient temperature following the second run. The vacuum held for an additional 17 days before the sample was baked to $330^{\circ} \mathrm{K}$ and cooled down before the third run. The helium gumping 


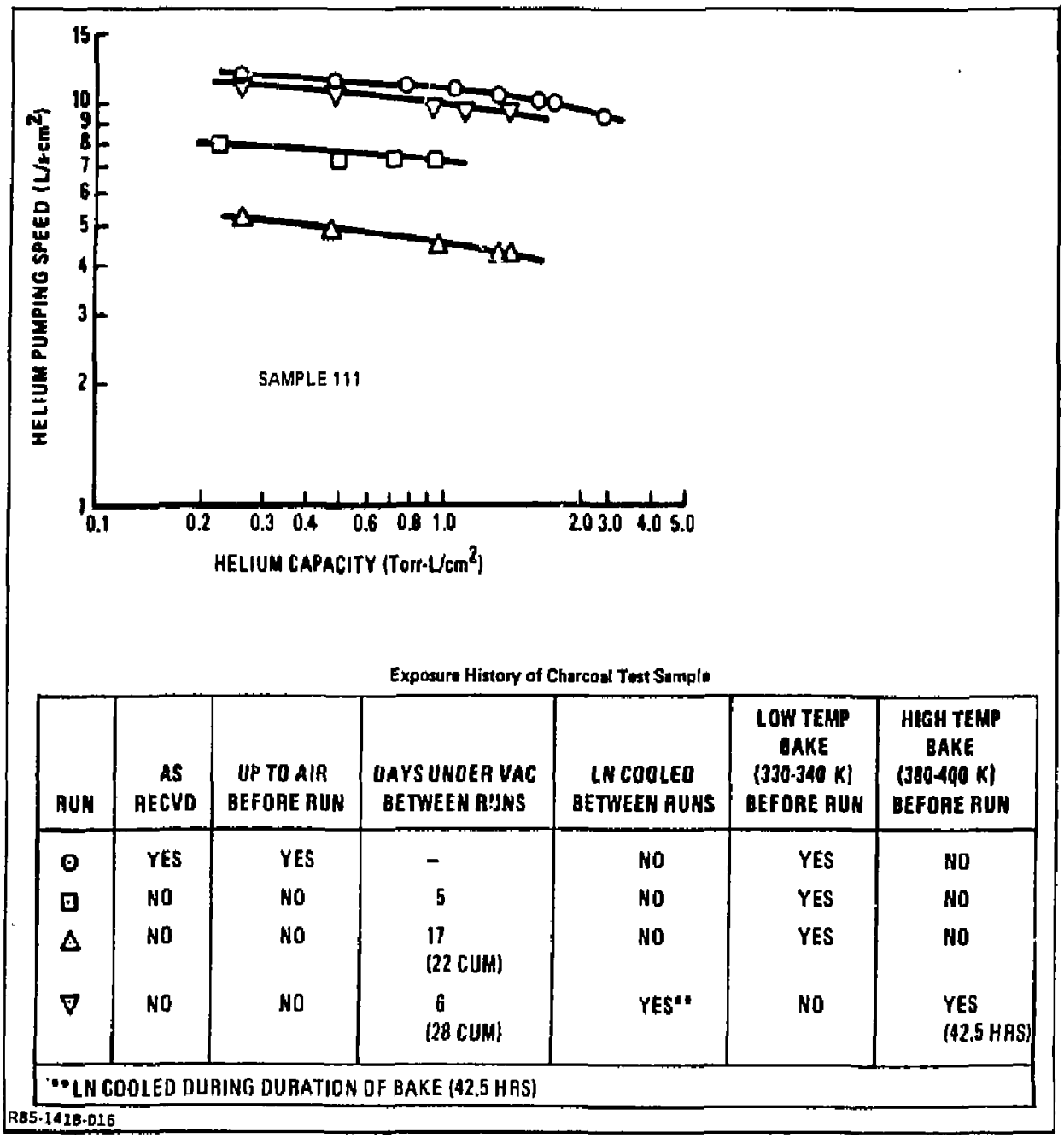

Fig. 9-6 Effect of Vecuum Exposure History on Chareogi Pumping Performance of Copper Cement Bonded Charcoal

speed after 20 min at the same helium throughput rate was reduced to approximately $4.51 \mathrm{~s}^{-1} \mathrm{~cm}^{-2}$, a $60 \%$ decrease compared to the performance of the as received sample.

The pump and sample were again allowed to warm to ambient while under vacuum, and ield under vacuum for an additional six days. At 42.5 hours before Run No. 4 , chevron cooldown with liquid nitrogen and sample bakeout was started. The LN cooling was continuous until completion of the run. Bakeout temperatures were increased to between $380^{\circ}$ and $400^{\circ} \mathrm{K}$ for a continuous $42.5 \mathrm{hr}$ period. The pump dewar was cooled with eryogenic he- 
lium for $90 \mathrm{~min}$ before the pump and sample stabilized. Helium pumping performance recovered to within $5 \%$ of the value attained by the as received sample in the first run. Pumping speed after 20 min of steady state helium throughput was $10.51 \mathrm{~s}^{-1} \mathrm{~cm}^{-2}$.

\subsection{TSTA PANEL TESTS}

This test series consisted of performance runs in which the liquid helium cooled, 16 in. $(40.6 \mathrm{~cm})$ diameter panel was exposed to consiant helium throughputs of 0.74 and

0.37 Torr liter $\sec ^{-1}$. These rates correspond to specific throughputs of $6 \times 10^{-4}$ and $3 \times 10^{-4}$ Torr $1 \mathrm{sec}^{-1} \mathrm{em}^{-2}$. The higher value corresponds to the specif ic throughput maintained in the tests of the $4 \mathrm{in.}(10.2 \mathrm{~cm})$ plates.

The panel was only vacuum baried prior to the first run while the shield surrounding the panel was maintained at liguid nitrogen temperature as long as the panel was in vacuum. Between the first and second run, the dewar was purged of liguid helium, warmed to $60^{\circ} \mathrm{K}$ to regenerate the helium gas, and recooled. The dewar was purged, allowed to warm up along with the liquid nitrogen shield, and recooled. The procedure between the third and fourth performance runs was the same as for the first run. No performance degradation was observed using the exposure methods described above.

Figure 9-? shows the pumping performance of the TSTA panel for the two throughputs. Performance was unaffected by throughput for the range of values tested. The data are based on the top gage reading within the thermal shield (Fig. 7-6), and are corrected for helium gage sensitivity, though not for thermomolecular effect.

The performance of the panel in a two-chevron compound (TS'A A) eryopump was estimated by correcting for the temperature effect as follows:

$$
\mathrm{s}=\mathrm{ts} \text { wo } \mathrm{To} / \mathrm{T} 1
$$

where $S$ is the projected helium pumping speed of the two chevron pump; $S_{\text {wo }}$ if the speed determined in these tests for the panel without baffle; To is the temperature of the incoming helium; $T 1$ is the temperature in the cold space inside the shield; and $t$ is the chevron transmissivity. Using a transmissivity based on Ref 4 of 0.15 for two chevrons in series, with $\mathrm{T} 1=90^{\circ} \mathrm{K}$ for the cold space temperature, the estimateo helium pumping performance for the compound pump is $4.91 \mathrm{sec}^{-1} \mathrm{~cm}^{-2}$. 


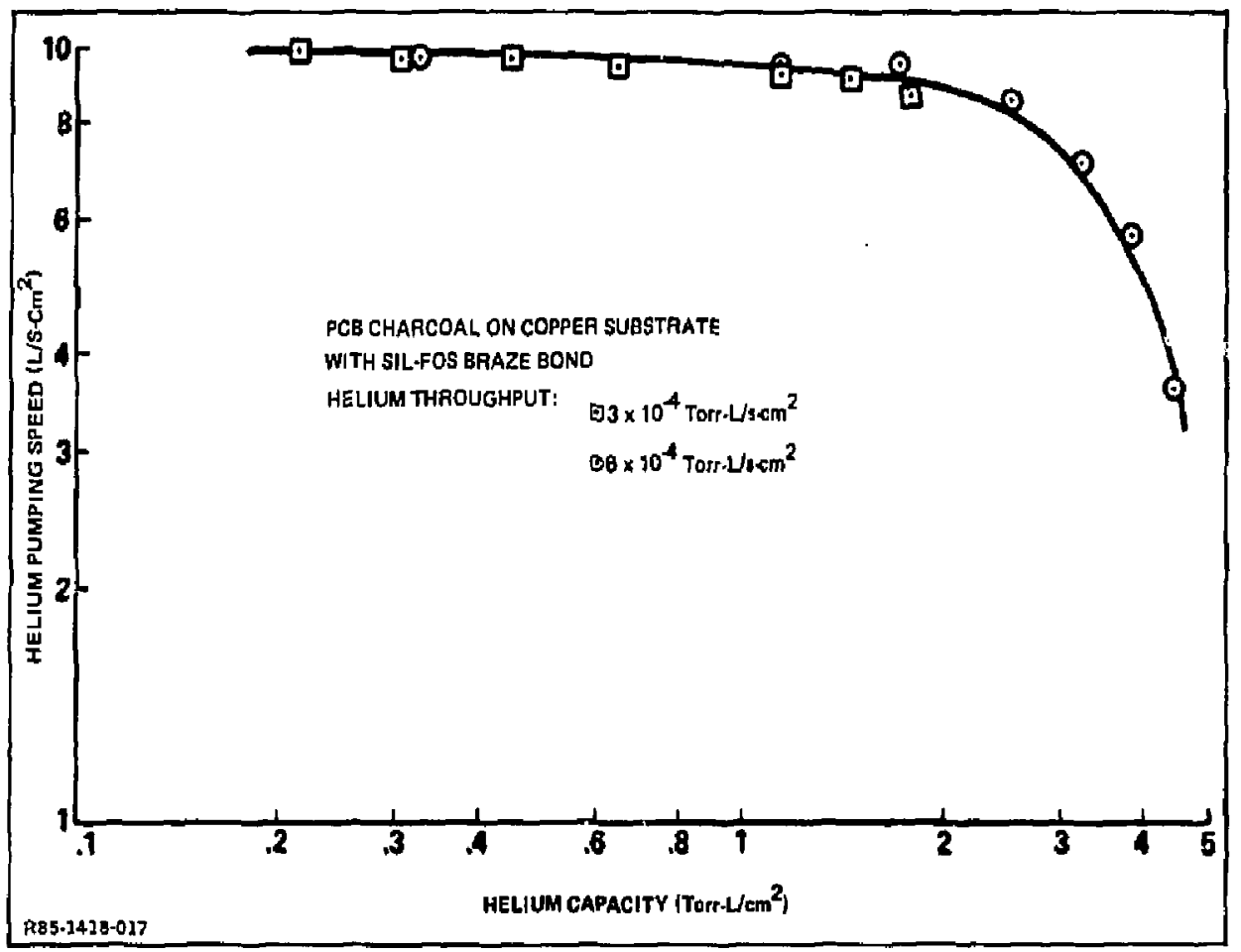

Fig. 9.7 Helium Pumping Performance of Sealed-up $40 \mathrm{~cm}$ Dia

Charcoal Cryopump Bonded with 6. whll Sil.Fas Braze

Examination of the apparatus after removal from the test chamber showed that some charcoal had dropped from the down facing panel. This condition is not expected to affect the panel's subsequent performance, as only the charcoal that was firmly attached to the bond and substrate contributed to the pumping capability. 


\section{0 - CHARACTERIZATION OF CHARCOAL}

In our prior work on charcaal characterization (Ref 1), it was shown that the PCB coconut charcoal exhibited superior helium pumping performance compared to the coal based charcoals BPL and Desorex. These differences are not explainable in terms of the atomic pore sizes of microscopic surface areas of each charcoal. To obtain a preliminary understanding of this phenomenon, both $\mathrm{X}$-ray diffraction and SEM techniques were used to identify possible differences in crystallinity and/or morphology of the charcoals.

Specimens of PCB and BPL charcoal were ground to powder and subjected to a powder diffractometer using $\mathrm{Cu}$ K $\alpha$ radiation. No crystalline peaks were observed in either powder sample. However, a broad enhancement of the background radiation was observed. This observation would indicate that both grades of charcoal are essentially amorphous. Therefore, no clear distinetion between the two grades can be made in terms of erystallinity.

The SEM evaluation, however, revealed some differences in the morphology of the external surfaces of the charcoal. Figure 10-1 illustrates typical appearance $(2000 \mathrm{X}$ ), of the PCB (coconut) and BPL (coal based) charcoals. As can be seen, the coconut chareoal contains significant areas of microporosity embedded in a lamellar-type surface structure. The visible pores are on the order of $5000 \AA\left(5 \times 10^{-5} \mathrm{~cm}\right)$, compared to the manufacturer's specification of $15-400 \AA$ A $\left(2.5 \times 10^{-7}\right.$ to $\left.10^{-6} \mathrm{em}\right)$, for the PCB and BPL charcosls which eannot be seen at $2000 \mathrm{X}$ magnification. The BPL charcoal appears to contain more irregularly shaped areas with much surface debris. No evidence of the microporosity observed in the PCB charcool can be seen in the BPL charcoal.

Although it is premature to clearly identify the reasons for differences in helium pumping speed based upon these cursory observations, it is passible that the greater degree of microporosity observed in the PCB charconl could permit better helium access into and out of the interior of the charcoal. This may be the first clue to those factors in the chareoal that could affect helium pumping performance. More work on the microchemistries and pore size distributions of the charcoal is needed before the explanation based upon morphological differences can be supported. 


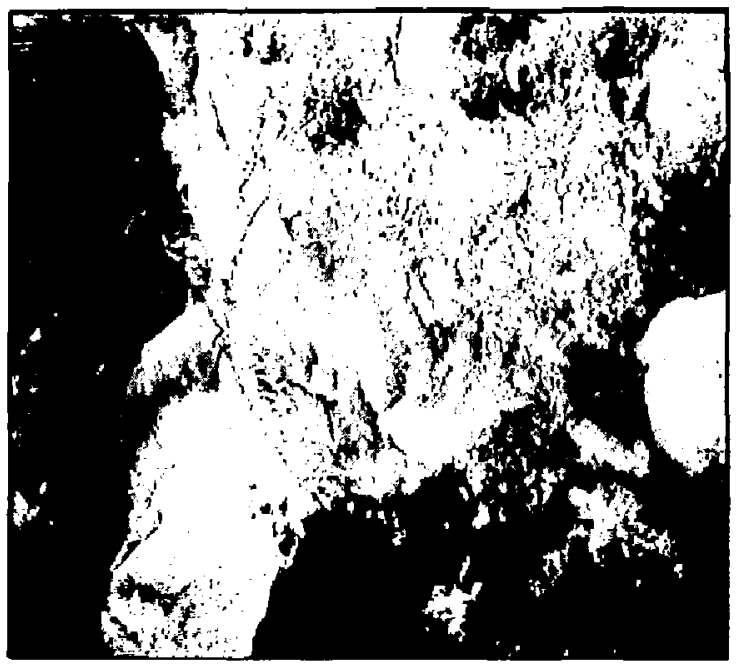

BPL COAL-BASED CHARCOAL (2000X)

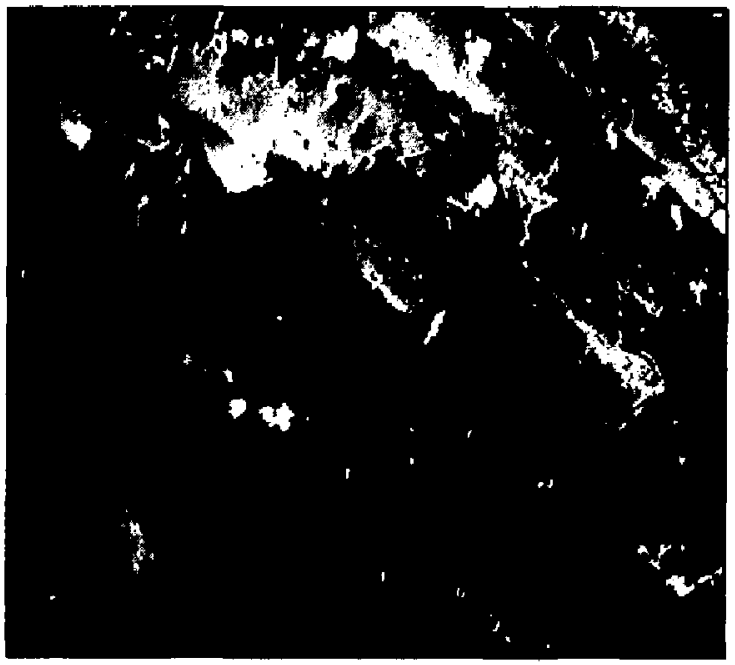

PCB COCONUT CHARCOAL (2000X)

Fig. 10-1 Microstructure of Charcoal Graniles 


\section{1 - DISCUSSION OF RESULTS}

On the basis of the results, it is cleal that the original objectives of this program have been met. The substrate thickness, the braze alloy thickness and the charconl particle size distribution have been optimized fon the range of variables investigated to yield helium pur ping performances that are reproducible and will meet anticipated fusion reactor reguirements for helium cryopumping. We identified a copper cement bond/charcoal combination which produces comparable performance, and offers the mariufacturing flexibility expected of a cement as compared to a braze. The chojce of either brazing or copper cement for the bonding agent can be made as a matter of convenience, cost, availability and geom etry.

Brazing techniques used in this program are suitable for producing flat charcoal pumping surfaces up to $28 \mathrm{in}^{2}\left(180 \mathrm{~cm}^{2}\right)$. However, it is anticipated that scale-up to larger sizes is possible with improvements in brazing practice. Brazing methods would bf difficult to apply to large complex shapes with curvilinear contours - as access and control of heat transfer to such shapes would be difficult to maintain. In such cases, the copper cement approach appears to be a preferred solution. Durability (i.e., adherence) of the charcoal particies on the substrate may be an issue for most bonding approaches. It was not possible to quantify the bond strength of the cilarcoal, although bond integrity was verified in a series of thermal cycle tests. The charcoal particles have quite irregular shapes and are held by a combination of shear and tension forces. The bonding interface between the charcoal and the bonding agent will influence the heat transfer characteristics as well as determine the durability of the charcoal cryopanel. One would anticipate that panels demonstrating high performance would also have good durability.

The effect on performance of cryopanel exposure to various environmental conditions has been demonstrated, but the cause and effect are not defined. Prolonged exposure of the charcoal to vacuum without liguid nitrogen shielding has an adverse effect on its subsequent helium pumping capability. However, use of liquid nitrogen shielding and bakeout restores the charcoal helium pumping performance. The fact that its capability can be restored is significant; the value of charcoal as a helium sorbent would be greatly diminished if the degradation were irreversible or unavoidable. 
The results greviously discussed are indicated by a limited number of tests and require additional investigation for verificatic $n$. The helium pumping performance of eharcoal is degraded if the charcoal at ambient temperature is exposed to vacuum for a prolonged time (from $16 \mathrm{hr}$ to several days), before it is cooled for pumping. A low temperature bake $\left(330^{\circ} \mathrm{K}\right)$ has no significant effect on improving the charcoal's performance. However, if the liguid nitrogen thermal shield surrounding the chartual is maintained during the prolonged time between runs, helium pumping performanee is subsequently high. Use of :iquid nitrogen shielding with a $400^{\circ} \mathrm{K}$ bakeout restored the charcoal's hiph performance. The common element in maintaining high performance appears to be the continued use of liquid nitrogen shielding during prolonged chareoal exposure to vacuum. The ghenomenon of ehareoal performance degradation have require further evaluation. Although the nature and source of the degradation have not been identified, it is likely that hydrocarbon contaminant and water vapor from the residual vacuum are the source. 
The major conclusions of this program are summarized, as follows:

- The charcoal particle size distribution (12×30 mesh) which produced the best helium pumping performance was confirmed as the optimum particle size. Both finer and coarser particle sizes showed diminished pumping speed and capacity

- Therraal cycle tests showed that both the braze and cement bonded charcoal/bond systems exposed to temperature excursions between $4^{\circ} \mathrm{K}$ and $77^{\circ} \mathrm{K}$ (a typical regeneration profile), and between $4 . \mathrm{K}$ and ambient (shutdown profile) remained intact after these tests

- Systems consisting of charcoal bonded with copper cement or with braze exceeded the demonstrated capability of the chareoal/epoxy bond standard

- Scale up of charcoal/braze samples imposes no size limitation

- A 16 in. $(40.6 \mathrm{~cm})$ jiameter charcoal cryopanel fabricated and installed in a TSTA compound cryopump showed high helium pumping performance with a projected specific speed of $4.91 \mathrm{~s}^{-1} \mathrm{~cm}^{-2}$ for a double chevron shielded pump

- Repeated or prolonged exposure to vacuum of an ambient temperature sample with no bake or with only a low temperature $\left(330^{\circ} \mathrm{K}\right)$ bake subsequently resulted in degraded pumping performance. Tests in which the sample was surrounded by a thermal shield held at liquid nitrogen temperature during vacuum exposure resulted in maintenance or restoration of the charcoal's pumping capability

- The superiority of coconut based charcoal may be related to the presence of micropores which could aid passage of helium into and out of the sorbent's interior. This tvpe sure was not present in the coal-based samples.

Based on the results of the cryopump development over the last two years, we recor 'nend that the following tasks be performed:

- Characterization of various charcoal grades to identify microstructural correlation with helium pumping performance

- Metallographic study of charcoal/bond interface

- Evaluation of charcual contamination

- Evaluation of aluminum substrates as an alternative to copper

- Seale up of copper cemented charcoal cryopanels

- Characterization of charcoal performance in co-pumping helium/hydrogen mixtures. 


\section{3 - REFERENCES}

1. Sedgley, D.W., Tobin, A.G., Batzer, T.H. and Call, W.R. "Development of Charcoal Sorbents for Helium Cryopumping"; 10 th Symposium on Fusion Engineering; Philadelphia, PA.; Dec 1983.

2. Coffin, D.O. and Walthers, C.R. "Vacuum Pumping of Tritium in Fusion Power Reactors"; 8th Symposium on Engineering Problems of Fusion Research; San Francisco, Nov 19 ?9.

3. Hseuh, H.C. and Worwetz, H.A. "Performance of BNL-TSTA Compound Cryopump"; Journal of Vactum Seience Techrology; 1981.

4. Santeler, Donald J, et ul, "Vacuum Technology and Space Simulation"; NASA SP-105; 1966. 